\title{
Vertical profiles of optical and microphysical particle properties above the northern Indian Ocean during CARDEX 2012
}

\author{
F. Höpner ${ }^{1}$, F. A.-M. Bender ${ }^{1}$, A. M. L. Ekman ${ }^{1}$, P. S. Praveen ${ }^{2}$, C. Bosch $^{3,6}$, J. A. Ogren ${ }^{4}$, A. Andersson ${ }^{3}$, \\ Ö. Gustafsson ${ }^{3}$, and V. Ramanathan ${ }^{5}$ \\ ${ }^{1}$ Department of Meteorology (MISU) and the Bolin Centre for Climate Research, Stockholm University, Stockholm, Sweden \\ ${ }^{2}$ International Centre for Integrated Mountain Development, Kathmandu, Nepal \\ ${ }^{3}$ Department of Environmental Science and Analytical Chemistry (ACES) and the Bolin Centre for Climate Research, \\ Stockholm University, Stockholm, Sweden \\ ${ }^{4}$ Earth System Research Laboratory, National Oceanic and Atmospheric Administration, Boulder, Colorado, USA \\ ${ }^{5}$ Scripps Institute of Oceanography, University of California, San Diego, California, USA \\ ${ }^{6}$ Environment and Energy, Fundació CTM Centre Tecnològic, Plaça de la Ciència 2, 08243 Manresa, Spain
}

Correspondence to: F. Höpner (friederike@misu.su.se)

Received: 19 December 2014 - Published in Atmos. Chem. Phys. Discuss.: 12 February 2015

Revised: 16 December 2015 - Accepted: 29 December 2015 - Published: 29 January 2016

\begin{abstract}
A detailed analysis of optical and microphysical properties of aerosol particles during the dry winter monsoon season above the northern Indian Ocean is presented. The Cloud Aerosol Radiative Forcing Experiment (CARDEX), conducted from 16 February to 30 March 2012 at the Maldives Climate Observatory on Hanimaadhoo island (MCOH) in the Republic of the Maldives, used autonomous unmanned aerial vehicles (AUAV) to perform vertical in situ measurements of particle number concentration, particle number size distribution as well as particle absorption coefficients. These measurements were used together with surface-based Mini Micro Pulse Lidar (MiniMPL) observations and aerosol in situ and off-line measurements to investigate the vertical distribution of aerosol particles.

Air masses were mainly advected over the Indian subcontinent and the Arabian Peninsula. The mean surface aerosol number concentration was $1717 \pm 604 \mathrm{~cm}^{-3}$ and the highest values were found in air masses from the Bay of Bengal and Indo-Gangetic Plain $\left(2247 \pm 370 \mathrm{~cm}^{-3}\right)$. Investigations of the free tropospheric air showed that elevated aerosol layers with up to 3 times higher aerosol number concentrations than at the surface occurred mainly during periods with air masses originating from the Bay of Bengal and the Indo-Gangetic Plain. This feature is different compared to what was observed during the Indian Ocean Experiment (INDOEX) conducted in winter 1999, where aerosol number concentrations
\end{abstract}

generally decreased with height. In contrast, lower particle absorption at the surface $\left(\sigma_{\text {abs }}(520 \mathrm{~nm})=8.5 \pm 4.2 \mathrm{Wm}^{-1}\right)$ was found during CARDEX compared to INDOEX 1999.

Layers with source region specific single-scattering albedo (SSA) values were derived by combining vertical in situ particle absorption coefficients and scattering coefficients calculated with Mie theory. These SSA layers were utilized to calculate vertical particle absorption profiles from MiniMPL profiles. SSA surface values for $550 \mathrm{~nm}$ for dry conditions were found to be $0.94 \pm 0.02$ and $0.91 \pm 0.02$ for air masses from the Arabian Sea (and Middle East countries) and India (and Bay of Bengal), respectively. Lidar-derived particle absorption coefficient profiles showed both a similar magnitude and structure as the in situ profiles measured with the AUAV. However, primarily due to insufficient accuracy in the SSA estimates, the lidar-derived absorption coefficient profiles have large uncertainties and are generally weakly correlated to vertically in situ measured particle absorption coefficients.

Furthermore, the mass absorption efficiency (MAE) for the northern Indian Ocean during the dry monsoon season was calculated to determine equivalent black carbon (EBC) concentrations from particle absorption coefficient measurements. A mean MAE of 11.6 and $6.9 \mathrm{~m}^{2} \mathrm{~g}^{-1}$ for 520 and $880 \mathrm{~nm}$, respectively, was found, likely representing internally mixed $\mathrm{BC}$ containing particles. Lower MAE values 
for 880 and $520 \mathrm{~nm}$ were found for air masses originating from dust regions such as the Arabian Peninsula and western Asia $\left(\operatorname{MAE}(880 \mathrm{~nm})=5.6 \mathrm{~m}^{2} \mathrm{~g}^{-1}, \operatorname{MAE}(520 \mathrm{~nm})=\right.$ $\left.9.5 \mathrm{~m}^{2} \mathrm{~g}^{-1}\right)$ or from closer source regions as southern India $\left(\operatorname{MAE}(880 \mathrm{~nm})=4.3 \mathrm{~m}^{2} \mathrm{~g}^{-1}, \operatorname{MAE}(520 \mathrm{~nm})=7.3 \mathrm{~m}^{2} \mathrm{~g}^{-1}\right)$.

\section{Introduction}

Anthropogenic aerosols influence the Earth's energy budget as aerosols can directly scatter and absorb solar radiation and affect cloud radiative properties (Boucher et al., 2013). Whereas the net direct radiative forcing of anthropogenic aerosols is an estimated cooling of $-0.35( \pm 0.5) \mathrm{Wm}^{-2}$, black-carbon (BC) containing particles contribute to a positive direct radiative forcing at the top of the atmosphere (TOA) of $+0.4(+0.05$ to +0.8$) \mathrm{Wm}^{-2}$ (Boucher et al., 2013).

The term BC is a qualitative description of light-absorbing carbonaceous substances, produced by fossil fuel combustion and biomass burning (Bond et al., 2013; Petzold et al., 2013). Lacking a uniform definition, BC measured by optical methods in the present study is referred to as the equivalent black carbon (EBC) in accordance with Petzold et al. (2013).

Even though BC is estimated to be one of the most important sources for human-caused changes in atmospheric heating next to carbon dioxide, its positive radiative impact is uncertain (Bond et al., 2013). A recent study by Samset et al. (2014) shows that global aerosol-climate models tend to overestimate the radiative forcing in remote regions and at high altitudes compared to an indicated general underestimation of global BC radiative forcing in atmospheric models (Bond et al., 2013; Andreae and Ramanathan, 2013). Thus, observations are still needed to gain a better understanding of $\mathrm{BC}$ physical and chemical properties. In situ measurements of the vertical profile of $\mathrm{BC}$-containing particles are of particular interest for radiative forcing calculations, but have been performed only occasionally (e.g. Babu et al., 2008, 2011; Corrigan et al., 2008; Wofsy, 2011; Oshima et al., 2012; Sheridan et al., 2012).

The emissions of anthropogenic aerosols, in particular absorbing aerosols, are still increasing in Asian countries such as China and India (Granier et al., 2011; Moorthy et al., 2013). During the dry winter monsoon season every year, polluted air masses from southern Asia are transported towards the northern Indian Ocean. Due to large-scale subsidence over the ocean during that period, the vertical dispersion of pollution is reduced and aerosol particles can be transported over long distances (Lelieveld et al., 2001; Lawrence and Lelieveld, 2010).

Several major field campaigns have been performed to investigate the advection of polluted air masses from southern Asia to the pristine northern Indian Ocean in winter time like, e.g., the Indian Ocean Experiment (INDOEX) in 1999, the Maldives Autonomous Unmanned Aerial Vehicle Cam- paign (MAC) and the Integrated Campaign for Aerosols, Gases and Radiation Budget (ICARB) in 2006, leading to the identification of an elevated aerosol layer above the marine boundary layer (MBL), referred to as an Atmospheric Brown Cloud (ABC) (e.g. Ramanathan et al., 2001; Sheridan et al., 2002; Franke et al., 2003; Corrigan et al., 2008; Moorthy et al., 2008). Previous studies have revealed a significant atmospheric heating and surface cooling by $\mathrm{ABCs}$ (e.g. Ramanathan et al., 2001, 2007b; Satheesh et al., 2008).

Aerosol measurements at the surface will not necessarily indicate the presence of elevated aerosol layers since the vertical exchange between the MBL and free troposphere (FT) can be weak (e.g. Corrigan et al., 2008). Thus, detailed vertical aerosol profiles are necessary to obtain complete information of the elevated aerosol layer composed of lightscattering and absorbing aerosols.

The present study is based on the field campaign Cloud Aerosol Radiative Forcing Experiment (CARDEX) (see also Ramanathan et al., 2011; Bosch et al., 2014; Pistone et al., 2015), which was conducted in the vicinity of the Maldives Climate Observatory in Hanimaadhoo (MCOH) from 16 February to 30 March 2012. CARDEX was conducted by the Scripps Institution of Oceanography at the University of California at San Diego, in collaboration with the Desert Research Institute, Stockholm University, Argonne National Laboratory and the Max Planck Institute in Hamburg. CARDEX augmented the existing measurement suite at the observatory to investigate the relationships between boundary layer turbulence, clouds, and absorbing soot aerosol. The CARDEX experiment is described in Ramanathan et al. (2011).

The focus of this study is in particular on the vertical profiles of long-range transported absorbing aerosols over the northern Indian Ocean under cloud-free conditions, utilizing a combination of surface and vertical in situ measurements as well as ground-based remote-sensing instruments.

$\mathrm{MCOH}$, located at $6.78^{\circ} \mathrm{N}, 73.18^{\circ} \mathrm{E}$ on one of the northernmost Maldives islands (Thiladhummathi Atoll) was founded as a part of the Atmospheric Brown Cloud project in 2004 to investigate the interaction between aerosols, radiation and climate over the Indian Ocean during different monsoon periods (Ramana and Ramanathan, 2006). During the winter monsoon and pre-monsoon, $\mathrm{MCOH}$ is a receptor site of long-range transported pollutants from emission regions of South Asia, the Middle East and Africa (Bosch et al., 2014). Local pollution levels are usually low since $\mathrm{MCOH}$ is at the northern tip of the island and the wind direction is dominantly north-easterly during the dry monsoon season (Ramana and Ramanathan, 2006). Therefore the Maldives islands in general, and $\mathrm{MCOH}$ in particular, offer favourable conditions for the study of processed anthropogenic aerosols.

Here, a detailed analysis of air mass origin is performed, relating source regions to microphysical and optical particle properties. Furthermore, typical vertical aerosol profiles occurring during the dry monsoon season are studied. In par- 
ticular, the dependence of single scattering albedo (SSA) on air mass source region is investigated. Vertical in situ measurements, performed with three autonomous unmanned aerial vehicles (AUAV) during CARDEX, are compared with aerosol extinction coefficients derived from ground-based lidar measurements. Furthermore, an approach for estimating particle absorption coefficients from lidar measurements and characteristic SSA profiles is presented, and evaluated against vertical in situ measurements (see Fig. 1). Hereby we investigate the possibility of using ground-based lidar measurements to determine and monitor the vertical distribution of absorbing aerosols in the area, and evaluate the main sources of uncertainty related to such an approach.

Air mass source- and site-specific mass absorption efficiencies (MAE) are calculated from surface absorption EC mass concentration measurements. This MAE is then used to estimate an EBC concentration from absorption coefficient measurements only.

\section{Experimental methods}

\subsection{Autonomous unmanned aerial vehicles}

One of the central components of CARDEX was the deployment of light-weight AUAVs to obtain vertical profiles up to $3 \mathrm{~km}$ of aerosol properties, radiation and turbulent fluxes as well as cloud microphysics. Robotic aircrafts were used already in the early 1990s to measure general meteorological parameters (Holland et al., 2001). The advanced instruments onboard the AUAV, used during CARDEX, were modified and developed at the Scripps Institution of Oceanography (Corrigan et al., 2008). The AUAVs were used in a stacked mode where up to three AUAVs were flown simultaneously at different altitudes.

Eighteen CARDEX research flights were performed from an airport, located around $3 \mathrm{~km}$ southwest of $\mathrm{MCOH}$, between 23 February and 26 March 2012. The payload on the aerosol AUAV was a TSI condensation particle counter (Model 3007) that measured the total particle number concentration for aerosol particles with diameter larger than $D_{\mathrm{p}}=10 \mathrm{~nm}$. The instrument accuracy of the AUAV CPC was within $\pm 10 \%$. Furthermore, an optical particle counter (OPC, MetOne Model 9722) that determines the particle number size distribution in eight channels between $D_{\mathrm{p}}=$ $0.3 \mu \mathrm{m}$ and $D_{\mathrm{p}}=3.5 \mu \mathrm{m}$ was installed. The OPC was calibrated with polystyrene latex (PSL) particles with a refractive index of $m=1.59+0.0 i$. Measurement artifacts due to rapid changes in temperature and humidity may have influenced the determination of the particle size (Corrigan et al., 2008).

A modified Magee AE-31 aethalometer that detects the attenuation of light of a particle-loaded filter for three wavelengths $(370,520,880 \mathrm{~nm})$ was also deployed. From the light attenuation, the particle absorption coefficient can be cal- culated according to the correction method of Arnott et al. (2005) with adaptations by Corrigan et al. (2006). Scattering and filter loading effects were accounted for with the values reported in Table 1 in Arnott et al. (2005) and Table 2 in Corrigan et al. (2006). Necessary particle scattering coefficients were calculated with Mie theory from vertical OPC and CPC measurements (see Sect. 2.5). The uncertainty of the AUAV aethalometer is considered to be lower than from the original seven-wavelength aethalometer (see Sect. 2.3) due to the reduction of the wavelengths (Corrigan et al., 2008). Extensive analysis of the seven-wavelength aethalometer deployed at $\mathrm{MCOH}$ gives an uncertainty range of 5-40\% (Corrigan et al., 2006).

General meteorological parameters such as relative humidity, pressure and temperature were also measured with a vertical resolution of 1-4 m.

The maximum flight time of the AUAV was $5 \mathrm{~h}$ (Corrigan et al., 2008). For detecting the particle absorption coefficients with the Aethalometer, the AUAV needed to stay at a constant altitude for about $20 \mathrm{~min}$ (level flight) because variations in pressure, temperature and relative humidity give an unstable signal (Corrigan et al., 2008). Thus, for each single flight, several level flights were performed, usually on the descending flight, to measure the particle absorption coefficient. Typically, a flight with the aerosol instrument took around $1.5 \mathrm{~h}$. A full description of the aerosol and radiation packages can be found in Corrigan et al. (2008) and Roberts et al. (2008). The stacked AUAV flights with aerosol and radiation measurements have been documented in Ramanathan et al. (2007b). The description of the turbulent water vapor flux measurement packages are given in Thomas et al. (2011). The package consists of the following: a turbulent gust probe; a fast response Crypton-Hygrometer water vapor sensor; an inertial navigation system (INS) coupled to global positioning system (GPS); and a $100 \mathrm{~Hz}$ data logging system (Thomas et al., 2011).

\subsection{Mini Micro Pulse Lidar}

In addition to the in situ measurements on the AUAV, a Mini Micro Pulse Lidar system (MiniMPL) from SigmaSpace was used to measure the elastic backscatter signal which can be transformed to $180^{\circ}$ particle backscatter and total particle extinction coefficients at $532 \mathrm{~nm}$ by using the Klett-method (see Sect. 2.6). The MiniMPL is based on standard MPL systems, first described by Spinhirne (1993) and Spinhirne et al. (1995). It has a single channel at $532 \mathrm{~nm}$ with a pulse repetition frequency (PRF) of $4000 \mathrm{~Hz}$. Transmitted laser pulses are scattered back from molecules, aerosols and clouds in the atmosphere. The backscattered signal is received by photodiode detectors and converted into a height profile by measuring the time between transmittance and detection of the laser pulse (Welton et al., 2002).

With the high PRF, a good signal-to-noise ratio can be achieved due to averaging many low-energy pulses in a short 
Table 1. Instruments used during CARDEX at $\mathrm{MCOH}$ and onboard the AUAV.

\begin{tabular}{lll}
\hline Instrument & Property & Measurement location \\
\hline SigmaSpace Mini Pulse Lidar (MPL) & $\begin{array}{l}\text { Vertical atmospheric backscatter } \\
\text { coefficient at } \lambda=532 \mathrm{~nm}\end{array}$ & MCOH \\
TSI Condensation particle & Total aerosol particle number \\
counter (CPC, model 3022) & $\begin{array}{l}\text { Particle scattering coefficient } \\
\text { TSI Nephelometer } \\
\text { (model 3563) }\end{array}$ & MCOH \\
Magee Aethalometer & $\lambda=450,550,700 \mathrm{~nm}$ & AUAV \\
(model AE-31) & Particle absorption coefficient & MCOH \\
Met One Optical particle & $\lambda=370,430,470,520,590,700,880 \mathrm{~nm}$ & AUAV \\
counter (OPC, model 9722) & Aerosol particle number & AUAV \\
AERONET sun photometer & size distribution $D_{\mathrm{p}}=0.3-3.5 \mu \mathrm{m}$ & $\mathrm{MCOH}$ \\
Thermal-optical transmission analyzer & (Absorption) Aerosol optical depth & MCOH \\
\hline
\end{tabular}

time (Spinhirne, 1993). The MiniMPL can detect the nearrange atmosphere from about $250 \mathrm{~m}$ up to $15 \mathrm{~km}$ with a vertical resolution of $30 \mathrm{~m}$. The low minimum range and high spatial resolution make the MiniMPL suitable for comparison with the in situ AUAV measurements.

The raw signal was corrected for different instrumental and background effects. In the near range of the telescope the signal can usually not be accurately imaged because of the difference in the transmitter and receiver field of view (overlap error) (Welton et al., 2002). Even though the overlap is considered to be $100 \%$ for the MiniMPL, a geometrical factor calibration, referred to as overlap here as well, has to be applied (SigmaSpace, personal communication, 2014). Furthermore, the photodiode detector can release photoelectrons during turn on already before triggering the laser pulse (Welton et al., 2000). This is called the afterpulse noise and needs to be corrected for. The so called background noise is caused by the sunlight. The measured signal in between two pulses is referred to as the background signal and must be subtracted from the final signal (Welton et al., 2000).

\subsection{Stationary instruments at the Maldives Climate Observatory Hanimaadhoo (MCOH)}

Continuous measurements of physical and chemical particle properties, solar radiation and meteorological parameters have been performed regularly at MCOH since 2004 . The instruments for measuring the solar radiation and meteorological parameters (temperature, relative humidity, pressure, wind, precipitation) were mounted on top of a $15 \mathrm{~m}$ tower, which is higher than the surrounding canopy. Hence, the local vegetation should not affect the measurements. The aerosol instruments were located inside the station and sampling of aerosols was done through a $15 \mathrm{~m}$ long inlet close to the tower. An impactor at the top of the inlet pipe ensured that particles with a diameter $D_{\mathrm{p}}>10 \mu \mathrm{m}$ were removed, resulting in collection of $\mathrm{PM}_{10}$ (particles with $D_{\mathrm{p}} \leq 10 \mu \mathrm{m}$ ).
The collection efficiency was better than $90 \%$ for particles with $D_{\mathrm{p}}=10 \mu \mathrm{m}$ and as high as $98 \%$ for particles with $D_{\mathrm{p}}<5 \mu \mathrm{m}$ (Corrigan et al., 2006).

$\mathrm{MCOH}$ data presented in this study are from several aerosol instruments. A condensation particle counter (TSI CPC, model 3022) measured the total aerosol particle number concentration between the particle diameters $D_{\mathrm{p}}=$ $10 \mathrm{~nm}$ and $D_{\mathrm{p}}=10 \mu \mathrm{m}$. The particle scattering coefficient $\left(\sigma_{\text {scat }}\right)$ at three different wavelengths $(450,550,700 \mathrm{~nm})$ was measured with a nephelometer (TSI, model 3563). The sampling air was not dried before the instruments inlet. However, relative humidities usually $\sim 10 \%$ below the ambient relative humidity were detected inside the nephelometer. The nephelometer data were corrected for truncation errors and instrument geometry characteristics (Anderson and Ogren, 1998). According to Bond et al. (2009) the utilized correction method leads to an error of the scattering coefficient up to maximum $5 \%$ depending on the SSA and the wavelength dependence of the absorption.

With a seven-wavelength aethalometer (Magee scientific, model AE-31), the particle absorption coefficient at 370, 430, $470,520,590,700$ and $880 \mathrm{~nm}$ was determined. The absorption coefficient $\left(\sigma_{\text {abs }}\right)$ was calculated from the aethalometer attenuation with the same correction method as described in Sect. 2.1. Scattering coefficients from the $\mathrm{MCOH}$ nephelometer were used to correct for the deposition of scattering aerosol particles on the filter.

For about half of the field campaign, aerosol number size distributions between $D_{\mathrm{p}}=0.5 \mu \mathrm{m}$ and $D_{\mathrm{p}}=10 \mu \mathrm{m}$ were measured by an aerodynamic particle sizer (TSI APS, model 3321).

A detailed descriptions of the MCOH observatory as well as the first annual cycle of the aerosol observations from $\mathrm{MCOH}$ are given in Ramanathan et al. (2007a). More information on the general instrumentation setup at $\mathrm{MCOH}$ can also be found in Corrigan et al. (2006) as well as Ramana and Ramanathan (2006). 


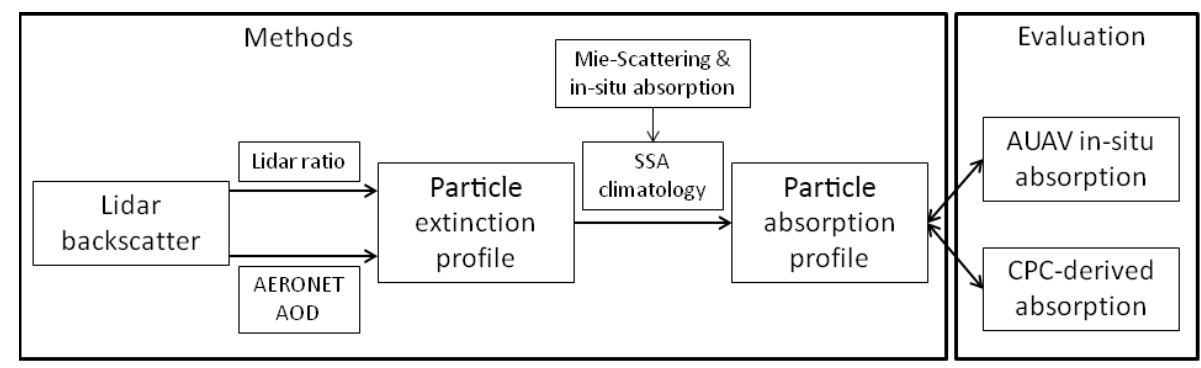

Figure 1. Flow chart describing the derivation of particle absorption profiles from lidar measurements, and their evaluation against in situ observations.

Furthermore, fine-particulate matter with particle diameters $D_{\mathrm{p}}<2.5 \mu \mathrm{m}\left(\mathrm{PM}_{2.5}\right)$ was sampled on pre-combusted quartz-filters for subsequent chemical analysis. Elemental carbon (EC) and organic carbon (OC) mass were determined with the NIOSH 5040 method by a thermal-optical transmission analyzer (Sunset Laboratory) after the field campaign (Bosch et al., 2014).

AERONET (AErosol RObotic NETwork) sun photometer measurements are performed continuously at $\mathrm{MCOH}$ and the ground-based passive remote- sensing instrument measures columnar aerosol optical depth (AOD) for several wavelengths (340-1640 nm) under clear sky conditions (Holben et al., 1998). Additionally, e.g., aerosol absorption optical depth (AAOD) and SSA values can be determined. AERONET data used in this study are quality-assured level 2.0 data. All described instruments are summarized in Table 1 .

\subsection{Trajectory analysis}

Seven-day-backward trajectories were used to determine the origin of the air masses arriving at $\mathrm{MCOH}$ in the MBL and FT. The trajectories were calculated with the HYSPLIT model developed by NOAA Air Resource Laboratory (Draxler, 1999). Backward trajectories arriving at heights of 400 and $2000 \mathrm{~m}$ were assumed to give a good indication for the air mass origin within the MBL and FT, respectively. This assumption is based on the lidar estimates of the MBL maximum height. Furthermore, trajectory height information was used to determine the vertical transport of the detected air masses. The data were sorted into three different air mass groups for subsequent analysis (see Sect. 3).

\subsection{Single scattering albedo profiles}

The single scattering albedo (SSA), defined as the ratio of $\sigma_{\text {scat }}$ to the particle extinction coefficient $\sigma_{\text {ext }}$

$\mathrm{SSA}=\frac{\sigma_{\text {scat }}}{\sigma_{\mathrm{ext}}}$

is an important particle property for describing the absorption ability of aerosols. $\sigma_{\text {ext }}$ is the sum of $\sigma_{\text {scat }}$ and $\sigma_{\text {abs. }}$. The SSA is also needed for deriving the absorption coefficient from lidar measurements (see Sect. 2.6).

The SSA for several wavelengths at the surface was determined from in situ absorption and scattering coefficient measurements at $\mathrm{MCOH}$ for this study. The uncertainty for the calculated surface SSA may be up to $10 \%$. The SSA is mainly influenced by the aerosol composition and size distribution, which are dependent on the air mass sources. Another important factor is the relative humidity since the particle scattering is enhanced by hygroscopic growth (e.g. Fitzgerald et al., 1982; Clarke et al., 2002; Zieger et al., 2013; Titos et al., 2014). As the air mass origin and relative humidity changes with height, the SSA may therefore also vary in the vertical column.

To determine the varying SSA in the column, vertically resolved particle absorption and scattering coefficient measurements are required. During the CARDEX research flights, vertical profiles of the particle absorption coefficient were measured with an onboard aethalometer. However, only a few measurements could be performed for each flight, as described in Sect. 2.1. Vertical profiles of the particle scattering coefficient were not measured, but can be calculated with Mie theory from vertical particle size distributions, that were determined from combined OPC and CPC measurements with the assumption of a bimodal size distribution. Particle sizes from the OPC measurements underestimate in general the real particle diameter for the most common atmospheric particles when calibrated with PSL. Hence, scattering coefficients calculated by Mie theory will be lower for the probed ambient particle population (Collins et al., 2000; Liu and Daum , 2000, e.g.). However, comparisons of calculated Mie scattering coefficients with $\mathrm{MCOH}$ surface measurements of particle scattering coefficients give the best agreement when using PSL refractive index in the Mie calculations. Thus, in this study a complex refractive index of $m=1.59+0.0 i$ was used in the calculations. The mean difference between the surface particle scattering and the calculated Mie scattering coefficients was $25 \%$ and is considered as uncertainty for Mie scattering coefficients.

Mie scattering coefficients were calculated at ambient relative humidity since the OPC measurements give ambient particle number size distributions in which particles may 
have changed in size and shape by hygroscopic growth compared to dry aerosol particles. Those particles are expected to be rather spherical because of hygroscopic growth, thus satisfying the assumption of Mie theory. Finally, scattering coefficient profiles were calculated for dry atmospheric conditions $(\mathrm{RH}=40 \%)$ with the hygroscopic enhancement factor found by Clarke et al. (2002) for the northern Indian Ocean in February and March.

$f(\mathrm{RH})=\frac{\sigma_{\text {scat }}(\mathrm{RH})}{\sigma_{\text {scat }}(\text { dry })}=0.841 \cdot\left(\frac{1-\mathrm{RH}}{100}\right)^{-0.368}$

Hygroscopic growth factors of aerosol particles above the Northern Indian Ocean during INDOEX were found to be between 1.6 and 2.0 on average for $90 \%$ relative humidity (Maßling et al., 2003). Similar scattering enhancement factors of 1.5 to 2 were detected in independent measurements in the same time period (Eldering et. al , 2001).

An SSA profile with four layers was utilized to account for variations in relative humidity and aerosol composition throughout the vertical column. SSA values in the MBL were based on surface measurements, while SSA in the three FT layers (700-1500, 1500-2500 and 2500-3000 m) were calculated from Mie scattering coefficients and individual in situ absorption coefficients. Mie scattering coefficients were scaled to the layer mean ambient relative humidity using Eq. (2). Mean SSA values in each layer were then established for different source regions (see Sect. 3.2). Figure S1 in the Supplement shows a flow chart for the complete determination of the SSA values.

SSA calculations from continuous AERONET sun photometer measurements were not used for further calculations because of temporal differences compared to the flight times. Only a small number of days with simultaneous AERONET SSA and flight data were available. Furthermore, an altitudedependent SSA is important for the following analysis and can not be provided from AERONET measurements. However, AERONET SSA is presented in Sect. 3.1.4 for comparison.

\subsection{Lidar-derived absorption}

With the aid of SSA profiles (see Sect. 2.5) we estimated an absorption coefficient and subsequently an EBC profile from MiniMPL measurements. With the following method, lidar measurements have the potential to provide continuous absorption coefficient profiles that can be compared to in situ measurements (see Fig. 1).

First, the extinction coefficient profile from the MiniMPL was calculated from the measured elastic backscatter signal and an assumed lidar ratio with the solution of the lidar equation presented by Fernald (1984) according to the method described in Klett (1981). The lidar ratio is defined as the ratio between extinction and $180^{\circ}$ backscatter coefficient. The lidar ratios used here are based on previous studies over the northern Indian Ocean in the winter monsoon season. For air masses arriving from the polluted northern part of the Indian subcontinent a lidar ratio of $65 \mathrm{sr}$ was used, while the lidar ratio for air coming from southern India, the southern Bay of Bengal and Indonesia was set to $50 \mathrm{sr}$, in accordance with Franke et al. (2003) and Müller et al. (2007) (see Sect. 3). A higher lidar ratio indicates larger absorption coefficients (Müller et al., 2003). A generalization of lidar ratios for specific air masses is certainly a source of error and might influence the determination of the extinction coefficient profiles. Lidar ratios can vary in the vertical column which is not considered in this study.

An alternative method for determining the lidar extinction coefficient is to use the AERONET AOD. The vertical integration of the extinction coefficient profile gives the columnar AOD. Thus, the lidar extinction coefficient can be constrained by the AERONET AOD through a recursive algorithm (Welton et al., 2000). This means in turn that the lidar ratio is assumed constant through the column which might not be valid for all profiles.

To determine the particle absorption coefficient from the lidar extinction coefficient profile, the SSA profiles as described in Sect. 2.5 for the lidar wavelength $532 \mathrm{~nm}$ are used.

$\sigma_{\mathrm{abs}}=\sigma_{\mathrm{ext}}-\sigma_{\mathrm{scat}}=\sigma_{\mathrm{ext}} \times(1-\mathrm{SSA})$

With a given mass absorption efficiency an EBC profile can be calculated from the lidar-derived absorption coefficient profile (see Sect. 2.8).

Uncertainties in absorption coefficients are dependent on the error in the SSA calculation that was estimated to be up to $50 \%$. Related possible sources of error are the accuracy of the in situ absorption coefficients and particle number size distribution measurements. Grouping by the air mass origin and height level may add additional uncertainties. Since lidar extinction coefficient profiles will be averaged over about $20 \mathrm{~min}$, the temporal variability will play a role as well. Standard deviations of the temporal average are used as uncertainty estimates of the extinction coefficient profiles.

\subsection{Evaluation methods}

Different methods were used to evaluate the lidar-derived absorption coefficient profiles. The most direct method is the comparison of the lidar-derived absorption coefficient profile with the measured profile of the absorption coefficient from the AUAV aethalometer. However, sparse in situ absorption coefficient data (with uncertainties of up to $40 \%$ ) make it challenging to compare the two different absorption coefficient profiles quantitatively.

Thus, an additional comparison method was used based on the assumption that the absorption coefficient can be related to the particle number concentration measured by the onboard CPC. According to Corrigan et al. (2008), a high correlation between the absorption coefficient and total particle concentration in the vertical is justified. $\mathrm{MCOH}$ surface measurements from winter 2006 and 2012 give a reasonable 

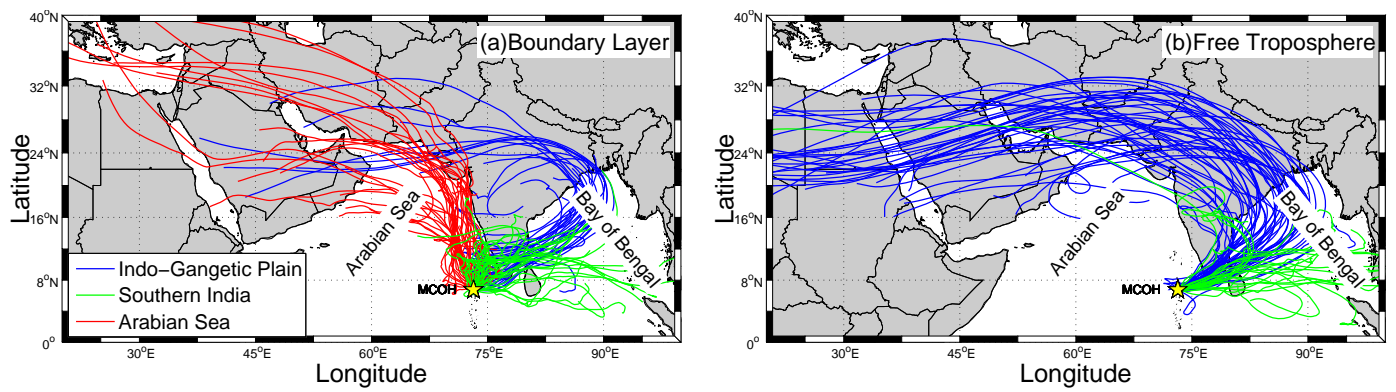

Figure 2. Seven-day-backward trajectories calculated by the HYSPLIT model arriving in the MBL at $400 \mathrm{~m}$ (a) and in the FT $2000 \mathrm{~m}$ (b) above MCOH at 00:00 and 12:00 UTC each day during CARDEX in February and March 2012. Colours represent the air mass source regions Indo-Gangetic Plain (blue), southern India (green) and the Arabian Sea (red).

linear correlation $\left(R^{2}=0.67\right)$ between total particle concentration and particle absorption coefficients for $520 \mathrm{~nm}$. To account for various aerosol types we used different linear relations $\sigma_{\mathrm{abs}}=a \times N(a-$ correlation factor, $N$ - total particle number concentration) for different air mass source regions, assuming similar compositions and optical properties for each air mass type. From that an absorption coefficient profile can be estimated from AUAV CPC measurements. Note, that the relations may have large uncertainties in the free troposphere since it can be decoupled from the marine boundary layer. This is a coarse method to verify if the lidar-derived absorption coefficient profiles give reasonable results.

\subsection{Mass absorption efficiency}

Additionally, an EBC mass concentration can be determined from particle absorption coefficient measurements using the mass absorption efficiency (MAE).

$\mathrm{EBC}=\frac{\sigma_{\mathrm{abs}}}{\mathrm{MAE}}$

MAE describes the efficiency of particle mass absorption and is typically given in $\mathrm{m}^{2} \mathrm{~g}^{-1}$. MAE varies for different aerosol compounds and mixtures and its value needs to be assumed or determined as a function of the aerosol type.

A CARDEX-specific MAE was calculated using $\sigma_{\text {abs }}$ for $880 \mathrm{~nm}$ and relating it linearly to the EC mass concentration from filter measurements (equivalent to EBC in Eq. 4). An inversely proportional relation between $\sigma_{\mathrm{abs}}(800 \mathrm{~nm})$ and the EC mass concentration as in Eq. (4) is valid since the particle absorption coefficient $\sigma_{\text {abs }}$ at $880 \mathrm{~nm}$ is considered to be dominated by $\mathrm{BC}$ absorption which can be approximately quantified by the filter-derived EC mass concentration (e.g. Yang et al., 2009). At lower wavelengths, other absorbing species as dust or organic carbon become more important for the particle absorption. The uncertainty of the MAE determination is dependent on the accuracy of the surface absorption coefficient measurements (up to $40 \%$ ) and the analysis of the EC filters. The results of the filter analysis were not compared with other analysis techniques which might add additional errors to the MAE results.

\section{Results and discussion}

\subsection{Relationship between aerosol particle properties and source region}

During CARDEX, polluted air masses from south and southeast Asia were transported to the Maldives by the northeast monsoon. Therefore, long-range transported polluted aerosols, including BC-containing particles, could be prevalently observed in February. Furthermore, aerosols, originating from western Asia as well as the Arabian Peninsula, likely including dust particles, were detected. Those air masses which crossed the Arabian Sea were observed mainly in March, towards the beginning of the pre-monsoon season when the surface wind typically changes to a northwesterly direction. Figure 2 shows the 7-day backward trajectories arriving at $\mathrm{MCOH}$ at 00:00 and 12:00 UTC in February and March in the MBL $(400 \mathrm{~m})$ and FT $(2000 \mathrm{~m})$. Altituderesolved trajectories showed that MBL air masses in general originated from below 1000 and $2000 \mathrm{~m}$ during the last 2 and 4 days, respectively. FT air masses arriving at $2000 \mathrm{~m}$ rarely originated from altitudes below $2000 \mathrm{~m}$.

Lidar profiles showed that the MBL height was typically between 400 and $800 \mathrm{~m}$ during CARDEX. Microwave radiometer measurements in combination with profiles of the meteorological parameters have shown that the cumulus cloud base typically coincides with the MBL top, indicated by a temperature inversion (Pistone et al., 2015). Visual observations confirmed frequent occurrences of haze layers and shallow convective clouds during CARDEX.

Three main air mass clusters were observed in the MBL:

1. Indo-Gangetic Plain (Pakistan and northern India) + Bay of Bengal (IGP),

2. Southern Asia + Bay of Bengal (+ Indonesia) (SI), 


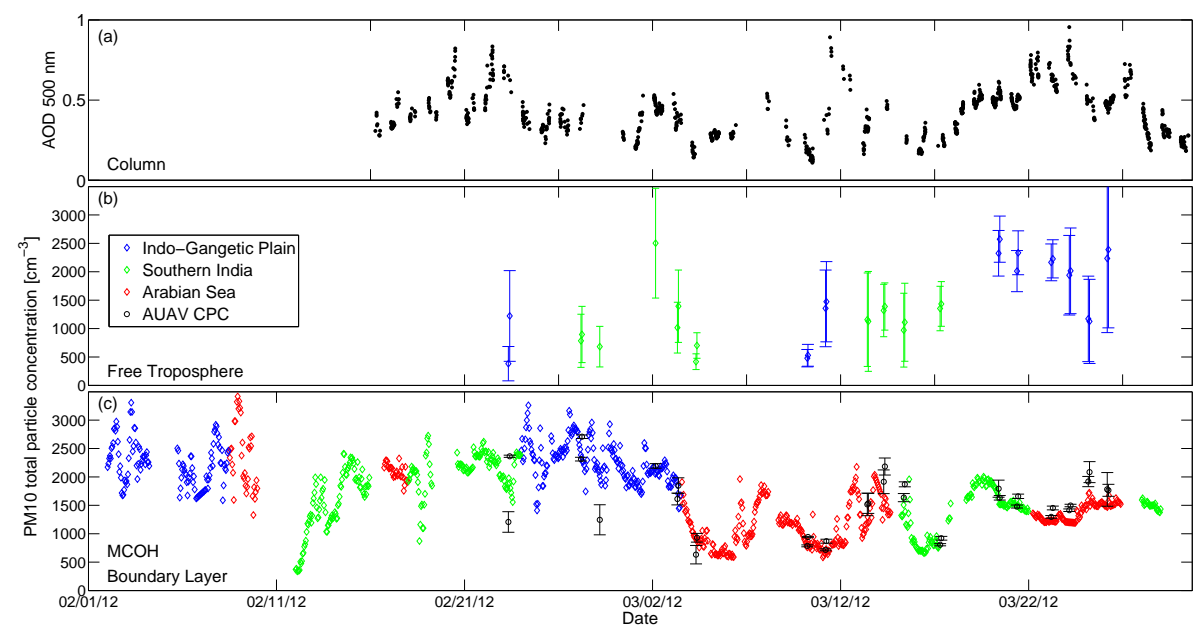

Figure 3. (a) Time series of AOD at $500 \mathrm{~nm}$ measured by AERONET sun photometer. (b) Time series of the mean total particle concentration with SD in the FT (1000-3000 m) measured by CPC onboard AUAV. (c) Time series of $\mathrm{PM}_{10}$ total particle concentration measured by CPC at $\mathrm{MCOH}$ (colored diamonds) and mean total particle concentration with SD in the MBL (0-500 m) (black circles) measured by the onboard AUAV CPC. The color coding corresponds to the trajectory cluster analysis shown in Fig. 2 (3 clusters in MBL and 2 clusters in FT).

\section{Arabian Sea and Arabian Peninsula, Iran, Pakistan or} Indian west coast (AS).

Those air mass clusters are in accordance to other studies at $\mathrm{MCOH}$ (e.g. Gustafsson et al., 2009; Engström and Leck, 2011; Bosch et al., 2014). Even though the Maldives are surrounded by ocean, only 2 days in the beginning of the campaign were dominated by pristine marine air masses from a southern direction in the MBL. During that time vertical profile measurements were not performed. Thus a marine air mass cluster is not included in the following analysis. In the FT, only the clusters IGP and SI were found. Each prevailing wind direction in the MBL and FT lasted for several days. Air masses were usually arriving from different clusters in the MBL and FT during CARDEX.

\subsubsection{Surface particle concentration}

The timeseries of $\mathrm{PM}_{10}$ total particle number concentration at $\mathrm{MCOH}$ and from the 18 research flights shown in Fig. 3 give an overview of the timing of the different air mass periods in the MBL and in the FT during CARDEX and the prior weeks. The MBL AUAV and MCOH surface measurements of particle number concentration are in good agreement (within $12.5 \%$ on average). The mean $\mathrm{PM}_{10}$ particle number concentration at $\mathrm{MCOH}$ and on the AUAV in the MBL were $1717 \pm 604$ and $1650 \pm 570 \mathrm{~cm}^{-3}$, respectively. Hourly mean aerosol number concentrations at $\mathrm{MCOH}$ ranged from 340 to $3500 \mathrm{~cm}^{-3}$. The lowest values were found during the short period with pure marine air mass origin (10 February p.m.12 February a.m.). Marine air masses are expected to have particle number concentrations between 200 and $800 \mathrm{~cm}^{-3}$ (Heintzenberg et al., 2000). This indicates that cases with particle number concentrations above $1000 \mathrm{~cm}^{-3}$ are likely to have been influenced by transported continental air masses or local emissions. However, local emissions were found to be low since the OC / EC ratio did not show any clear diurnal cycle which suggests no significant influence from local photochemical processes (Bosch et al., 2014).

Air masses transported with the northeasterly winds from the Indian subcontinent and the Bay of Bengal (cluster IGP) had the highest aerosol number concentrations with an average of $2247 \pm 370 \mathrm{~cm}^{-3}$. Those air masses are likely to have passed over the highly polluted Indo-Gangetic Plain in northern India and Pakistan. The mean aerosol number concentrations for the Arabian sea (cluster AS) and southern India (cluster SI) aerosols were $1375 \pm 531$ and $1660 \pm 523 \mathrm{~cm}^{-3}$, respectively. Aerosols from SI passed only over the southern tip of India where the particle number concentration and emissions are typically lower than, e.g., in northern India (Dey and Di Girolamo, 2010). However, some of those air masses may have passed urban areas in southern India like Bangalore, Chennai or Trivandrum which are known for high aerosol concentration (Moorthy et al., 2005). Air masses from AS are likely influenced by dust from desert regions in South Asia or the Arabian Peninsula. AS air masses may be as well transported along the urban Indian west coast which can result in higher particle number concentration as seen, e.g., on 9 and 10 February or 12 to 14 March.

The lower mean particle number concentration for SI and AS are supported by long-term satellite observations, which show significantly lower AOD values $(558 \mathrm{~nm})$ over the Arabian Sea and southern India compared to IGP and the northern Bay of Bengal for the winter and pre-monsoon season (Moorthy et al., 2008; Dey and Di Girolamo, 2010). 

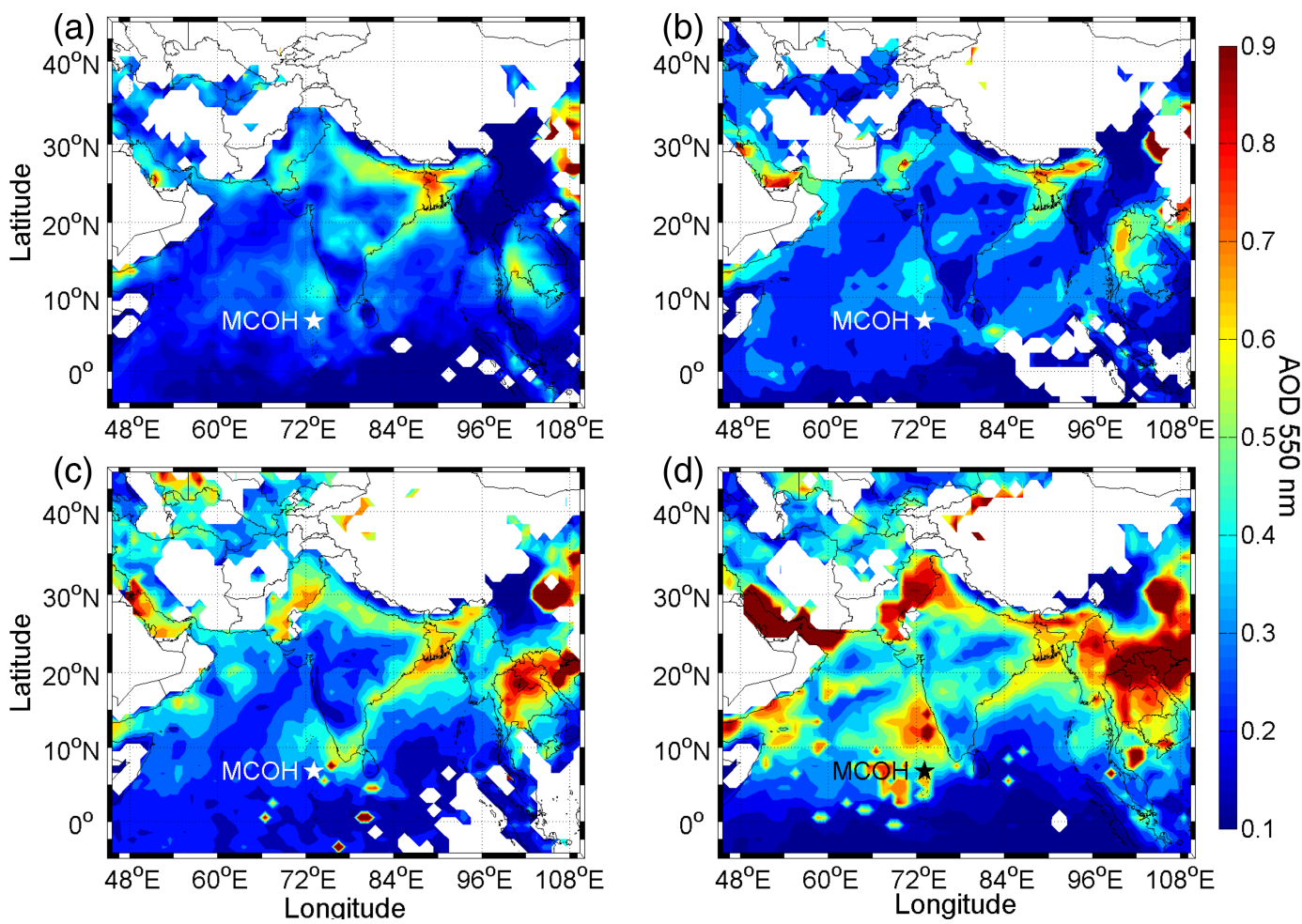

Figure 4. Mean AOD at $550 \mathrm{~nm}$ derived from measurements by the MODIS instrument onboard the Terra satellite. (a) 1 until 14 February 2012, (b) 15 until 29 February 2012, (c) 1 until 15 March 2012. (d) 16 until 31 March 2012.

\subsubsection{AOD}

There was a general decrease in the aerosol particle number concentration at the surface from February to March. However, no decrease in AERONET AOD at $500 \mathrm{~nm}$ was found. The surface particle number concentration variations do not correlate with the AOD variation $\left(R^{2}=0.04\right)$ (see Fig. 3a and c). The columnar AOD varies between 0.2 and 0.9 with a mean $\operatorname{AOD}(500 \mathrm{~nm})=0.42 \pm 0.15$.

Figure 4 shows the mean AOD field at $550 \mathrm{~nm}$ over the northern Indian Ocean and Indian subcontinent derived from the satellite-based MODIS instrument (Moderate Resolution Imaging Spectroradiometer) on Terra (e.g. King et al., 2003) for four consecutive 2-week periods from 1 February until 31 March 2012 (MODIS collection 5.1 data). High AOD values above the Indo-Gangetic Plain and the outflow region above the Bay of Bengal close to the Indian East coast can be seen in all four time periods. Increasing AOD above the Arabian Sea and southern Asia towards the end of the campaign is consistent with the seasonal development seen in long-term satellite observations shown in Dey and Di Girolamo (2010). March marks the beginning of the pre-monsoon season and northwesterly to westerly winds at the surface transport mainly dust to the Arabian Sea and northern as well as central India. The relatively high mean AOD during the last period of the field campaign, seen in Figs. $3 \mathrm{a}(\mathrm{AOD}(500 \mathrm{~nm})>0.6)$ and $4 \mathrm{~d}$, must be caused by high aerosol concentrations above the mixed layer and/or large dust or sea salt particles in the MBL since only relatively low particle number concentration were found in the MBL (see Fig. 3c). Relatively high particle number concentrations in the FT during the last six flights (see Fig. 3b) indicate that an increase in the FT aerosol burden may have contributed to the high AOD values. In addition, the timeseries of the lidar extinction coefficient from 20-26 March in Fig. S2 show high extinction coefficients in the MBL. This can be either a sign of large particles and/or high relative humidity which leads to high backscatter signals.

\subsubsection{Vertical particle number concentration profiles}

Between 1000 and $3000 \mathrm{~m}$ altitude, the particle number concentration is quite variable, as indicated by the standard deviation (SD) shown in Fig. 3b. The 18 research flights with the AUAVs could measure $\mathrm{PM}_{10}$ particle number concentration in situ during different air mass periods in the MBL and FT. The particle number concentrations in the FT were up to 3 times higher than the concentration in the MBL during elevated pollution plume episodes. Those elevated aerosol layers were mostly unrelated to the surface aerosol concentration. This indicates a boundary layer decoupled from the free troposphere. Only a weak correlation between FT and MBL particle number concentration could be found $\left(R^{2}=0.31\right)$, in general agreement with Corrigan et al. (2008), who found 
a correlation coefficient of $R^{2}=0.42$ at $\mathrm{MCOH}$ in March 2006.

Figure $5 \mathrm{~b}$ and $\mathrm{c}$ show the median $\mathrm{PM}_{10}$ particle number concentration profiles for the different source regions in the MBL and FT for CARDEX. The particle number concentration is in general rather constant throughout the MBL, as expected for a well-mixed MBL. Periods with aerosols transport from IGP and the Bay of Bengal (four fligths) generally have a higher particle number concentration in the MBL compared to air originating from southern India (five flights) and the Arabian Sea (nine flights).

Half of the flights were performed during conditions with FT flow from IGP. Even if the variability is quite large, it is clear that an elevated aerosol layer in the FT appears more often during periods of long-range transport from IGP, whereas air masses arriving from southern India show a decrease of the particle number concentration with height on average.

The median $\mathrm{PM}_{1}$ number concentration profile is shown in Fig. 5a together with the corresponding profiles from the field campaigns INDOEX (de Reus et al., 2001) in February and March 1999 and MAC (Corrigan et al., 2008) in March 2006. Significantly higher particle number concentrations were detected in 2006 and 2012 compared to INDOEX in 1999, in particular above the MBL. The 23 research flights performed during INDOEX showed a mean particle number concentration for particles bigger than $D_{\mathrm{p}}=6 \mathrm{~nm}$ of $1194 \pm 635 \mathrm{~cm}^{-3}$ in the mixed layer up to $1 \mathrm{~km}$ over the Maldives Islands (de Reus et al., 2001) compared to $1215 \pm 350 \mathrm{~cm}^{-3}$ for particles bigger than $D_{\mathrm{p}}=10 \mathrm{~nm}$ during MAC. The mean particle number concentration during CARDEX was as large as $1520 \pm 740 \mathrm{~cm}^{-1}$ for particles bigger than $D_{\mathrm{p}}=10 \mathrm{~nm}$. The difference above the MBL is even larger.

A higher columnar aerosol load in 2006 and 2012 could be explained with a general increase in emissions over Asia. Several emission inventories show that the $\mathrm{BC}, \mathrm{NO}_{\mathrm{x}}$ and $\mathrm{SO}_{2}$ emissions over India have increased between 1999 and 2010 (Granier et al., 2011). Long-term observations in India showed also that AOD $(500 \mathrm{~nm})$ is increasing at a rate of $2.3 \%$ on average compared to 1985 (Moorthy et al., 2013). Another reason for differences in aerosol concentration above the MBL can be different meteorological conditions during the different field campaigns. According to Verver et al. (2001), major wind and relative humidity anomalies were observed in 1999. Especially in February 1999, a stronger northern convergence zone occurred compared to the climatological monthly mean circulation between 1990 and 1999. Verver et al. (2001) identified several convective precipitation events in February 1999 which may have influenced the aerosol particle concentration significantly through wet removal.

The particle number concentration profiles show a completely different structure in 1999, 2006 and 2012. While the INDOEX (1999) vertical profile shows a decrease in particle number concentration with height, the distinct peaks between 1000 and $2500 \mathrm{~m}$ detected in the MAC and CARDEX profiles indicate that elevated aerosol layers were associated with larger particle number concentrations or more frequently occuring during the two later campaigns. A small variability for the INDOEX profile indicates similar particle number concentration for all flights. The variability in vertical profiles of particle number concentration during MAC and CARDEX on the other hand is larger. As elevated aerosol layers mainly occur with air masses from IGP and the Bay of Bengal, the difference in particle concentration at higher altitudes could mean that more cases with IGP affected air in the FT were detected during MAC 2006 compared to CARDEX and INDOEX.

Even though elevated aerosol layers were identified by vertical optical measurements during INDOEX (see e.g. Ramanathan et al., 2001; Sheridan et al., 2002; Franke et al., 2003), higher aerosol concentration above the MBL were not detected with in situ flight measurements of particle number concentration (see Fig. 5a). Possible explanations could be differences in meteorology, timing as well as measurement area between the different INDOEX measurements and compared to MAC and CARDEX. The flights described by de Reus et al. (2001) during INDOEX cover a large area around the Maldives with measurements as far south as over the southern Indian Ocean $\left(\sim 7^{\circ} \mathrm{N}-7^{\circ} \mathrm{S}\right.$ and $67-$ $79^{\circ} \mathrm{E}$ ). However, one would expect a greater variation for such a large measurement area which is not the case for the INDOEX flights.

\subsubsection{Surface particle optical properties}

Table 2 gives an overview of the measured optical properties at $550 \mathrm{~nm}$ at $\mathrm{MCOH}$ and of the AUAV data compared to previous field campaigns. All properties are given for $\mathrm{RH}<40 \%$, partly calculated with Eq. (2). The particle absorption is related to the air mass source in a similar way as the particle number concentration. For CARDEX, the highest mean particle absorption coefficient, $11.2 \pm 2.2 \mathrm{Mm}^{-1}$, was found for aerosols from IGP and the Bay of Bengal. Significantly lower mean absorption coefficients were measured in air masses from southern India $\left(8.4 \pm 4.5 \mathrm{M} \mathrm{m}^{-1}\right)$ and the Arabian Sea $\left(5.6 \pm 2.8 \mathrm{Mm}^{-1}\right)$.

Compared to 1999, the absorption coefficient is smaller in the whole column while the scattering coefficient is larger at the surface. The mean absorption coefficient measured at MCOH in February and March 2006 is similar to that measured in 1999, but the mean particle scattering coefficient in the MBL is instead comparable to CARDEX. Higher scattering coefficients in 2006 and 2012 are in agreement with the higher particle number concentrations. Lower absorption coefficients in 2012 could possibly be explained by changes in emissions over southern Asia. As a consequence of higher particle scattering and lower absorption coefficients the SSA was higher in 2012 and 2006 compared to 1999.

A comparison between ambient surface SSA for $450 \mathrm{~nm}$ and AERONET SSA for $439 \mathrm{~nm}$ shows a weak correla- 

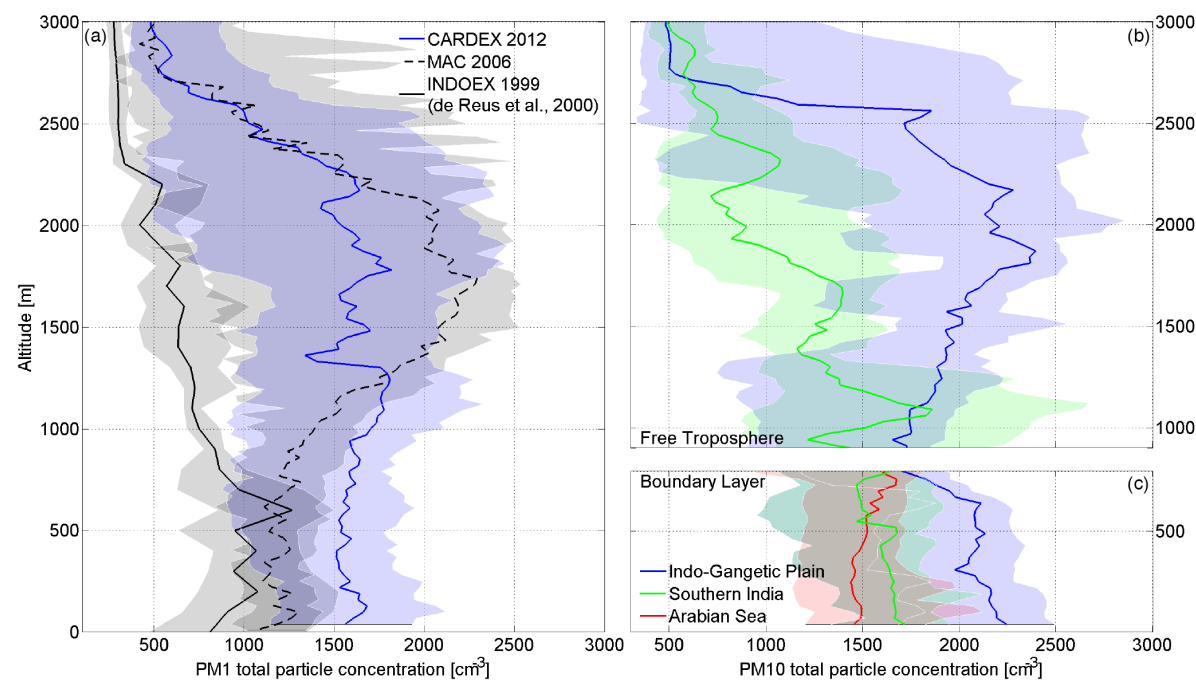

Figure 5. (a) Vertical profile of the median $\mathrm{PM}_{1}$ particle number concentration during CARDEX (blue), MAC (black dashed) and INDOEX (black solid) with 25 and $75 \%$ percentiles, measured by a CPC onboard the AUAV. (b) and (c) Median PM 10 particle number concentration during CARDEX with 25 and $75 \%$ percentiles in the FT and MBL, respectively for air masses originating from the Indo-Gangetic Plain, southern India and Arabian sea (blue, green, red).

Table 2. Mean particle properties during CARDEX at the surface and in some cases above the MBL at dry conditions $(\mathrm{RH}<40 \%)$ compared to MAC 2006 and INDOEX 1999. Particle properties for CARDEX are given for the different source regions, Indo-Gangetic Plain (IGP), southern India (SI) and Arabian Sea (AS), for BL and FT.

\begin{tabular}{|c|c|c|c|}
\hline $\begin{array}{l}\text { Parameter } \\
\text { wavelength }\end{array}$ & CARDEX 2012 & MAC 2006 & $\begin{array}{l}\text { INDOEX } 1999 \\
\text { (Sheridan et al., 2002) }\end{array}$ \\
\hline absorption & BL IGP $11.2 \pm 2.2$ & \multirow{4}{*}{ BL $13.8 \pm 5.4$} & \multirow{3}{*}{ BL $14 \pm 7$} \\
\hline coeff. $\left(\mathrm{Mm}^{-1}\right)$ & BL SI $8.4 \pm 4.5$ & & \\
\hline $550 \mathrm{~nm}$ & BL AS $\quad 5.6 \pm 2.8$ & & \\
\hline & FT IGP $12.7 \pm 6.0$ & & $1-3 \mathrm{~km} 16 \pm 10$ \\
\hline scattering & BL IGP $112 \pm 33$ & \multirow{4}{*}{ BL $88.9 \pm 41.2$} & \multirow{4}{*}{ BL $63 \pm 29$} \\
\hline coeff. $\left(\mathrm{Mm}^{-1}\right)$ & BL SI $80 \pm 29$ & & \\
\hline $550 \mathrm{~nm}$ & BL AS $81 \pm 40$ & & \\
\hline extinction & BL IGP $123 \pm 34$ & & \\
\hline coeff. $\left(\mathrm{Mm}^{-1}\right)$ & BL SI $88 \pm 33$ & \multirow[t]{2}{*}{ BL $138 \pm 37$} & \multirow[t]{2}{*}{ BL $83 \pm 48$} \\
\hline $550 \mathrm{~nm}$ & BL AS $87 \pm 42$ & & \\
\hline SSA & BL IGP $0.91 \pm 0.02$ & \multirow[b]{2}{*}{ BL $0.90 \pm 0.03$} & \multirow[b]{2}{*}{ BL $0.81 \pm 0.04$} \\
\hline $550 \mathrm{~nm}$ & $\begin{array}{l}\text { BL SI } 0.91 \pm 0.02 \\
\text { BL AS } 0.94 \pm 0.02\end{array}$ & & \\
\hline
\end{tabular}

tion $\left(R^{2}=0.04\right)$ and general higher surface values than the AERONET SSA. The averaged AERONET SSA values for $439 \mathrm{~nm}$ and $675 \mathrm{~nm}$ for the different source regions in the MBL are given in Table 3. However, AERONET SSA data were only available for 16 days for the 2-month campaign period. Furthermore, AERONET calculates the SSA for the whole column which will be influenced by potential elevated aerosol layers.

\subsection{Vertical profiles of particle optical properties}

Vertical profiles of particle optical properties were derived from MiniMPL and in situ aerosol measurements. Particle extinction coefficient profiles were determined from MiniMPL measurements at $532 \mathrm{~nm}$. Particle size distributions from OPC measurements onboard the AUAV were used to calculate particle scattering coefficients with Mie theory. Furthermore, mean SSA values at $532 \mathrm{~nm}$ for different height levels and air masses were defined with Mie scattering coefficients and in situ absorption coefficient measurements on- 
Table 3. Coefficients used to describe the relationship between particle absorption $\left(\sigma_{\text {abs }}\right)$ and particle number concentration $N$ for different source regions. Also shown is the mean SSA for various height levels used to calculate the lidar-derived absorption coefficients as well as the AERONET SSA at ambient relative humidity.

\begin{tabular}{llll}
\hline Parameter & Indo-Gangetic Plain & Southern India & Arabian Sea \\
\hline$\sigma_{\text {abs }}$ & $5.02 \times 10^{-3} \cdot N$ & $5.33 \times 10^{-3} \cdot N$ & $4.24 \times 10^{-3} \cdot N$ \\
$(532 \mathrm{~nm})\left(\mathrm{Mm}^{-1}\right)$ & $R^{2}=0.35$ & $R^{2}=0.48$ & $R^{2}=0.63$ \\
SSA surface & $0.94 \pm 0.014$ & $0.94 \pm 0.016$ & $0.96 \pm 0.012$ \\
$(532 \mathrm{~nm})$ & $($ at $\mathrm{RH}=80 \%)$ & $($ at $\mathrm{RH}=80 \%)$ & $($ at $\mathrm{RH}=80 \%)$ \\
SSA 700-1500m & $0.88 \pm 0.026$ & $0.89 \pm 0.11$ & $\mathrm{x}$ \\
$(532 \mathrm{~nm})$ & $($ at $\mathrm{RH}=75 \%)$ & $($ at $\mathrm{RH}=65 \%)$ & \\
SSA $1500-2500 \mathrm{~m}$ & $0.82 \pm 0.11$ & $0.85 \pm 0.11$ & $\mathrm{x}$ \\
$(532 \mathrm{~nm})$ & $($ at $\mathrm{RH}<40 \%)$ & $($ at $\mathrm{RH}=65 \%)$ & \\
SSA 2500-3000m & $0.82 \pm 0.14$ & $0.94 \pm 0.04$ & $\mathrm{x}$ \\
$(532 \mathrm{~nm})$ & $($ at $\mathrm{RH}<40 \%)$ & $($ at RH $=65 \%)$ & \\
SSA AERONET & $0.91 \pm 0.02$ & $0.92 \pm 0.02$ & $0.92 \pm 0.02$ \\
$(439 \mathrm{~nm})$ & & & \\
SSA AERONET & $0.89 \pm 0.05$ & $0.91 \pm 0.03$ & $0.93 \pm 0.01$ \\
$(675 \mathrm{~nm})$ & & & \\
\hline
\end{tabular}

board the AUAV. These SSA values were utilized to calculate absorption coefficient profiles from the lidar extinction coefficient profiles. Detailed methods, assumptions and related uncertainties are described in Sect. 2.

Additionally, evaluation of the lidar-derived absorption coefficient profiles was performed, using the vertical in situ absorption coefficient measurements as well as simplified absorption coefficient profiles calculated from a linear correlation between particle concentration and the absorption coefficient at the surface (see Sect. 2.7). Table 3 lists those relations used for the AUAV CPC based absorption coefficient (at $532 \mathrm{~nm}$ ). Note that the relations may not be representative for the whole column since the air masses above the MBL can have aerosol particles with different chemical composition and particle properties even though the air mass originates from the same source region (Corrigan et al., 2008).

Table 3 also shows SSA values at $532 \mathrm{~nm}$ for four different altitude ranges and at air mass specific relative humidity which was determined from mean $\mathrm{RH}$ profiles. The relative humidity in the MBL was on average increasing towards the top of the MBL and was set to $80 \%$ for the SSA calculations for all cases since no major differences were found for different source regions. As discussed by Pistone et al. (2015), the FT was observed to be either "wet" or "dry". Low relative humidities were mainly detected during periods with air masses from IGP. This is consistent with the typical largescale subsidence over the northern Indian Ocean (Pistone et al., 2015). The mean SSA for IGP air masses above $1500 \mathrm{~m}$ was calculated to be 0.82 for "dry" atmospheric conditions $(\mathrm{RH}<40 \%)$. In the lowest FT $(700-1500 \mathrm{~m})$, SSA was calculated for $\mathrm{RH}=75 \%$ to $0.88 \pm 0.026$ (at $532 \mathrm{~nm}$ ). "Wet" conditions occurred when air masses arrived from southern India and Indonesia (Pistone et al., 2015). The relative humidity for SSA calculation was set to $\mathrm{RH}=65 \%$ through the whole FT. SSA in the upper part of the measurement range (2500-3000 m) was calculated to be $0.94 \pm 0.04$ while the SSA between 700 and $1500 \mathrm{~m}$ was similar to the SSA for IGP influenced aerosols but with larger variation $(0.89 \pm 0.11)$.

Vertical SSA results based on lidar measurements from INDOEX performed by Müller et al. (2003) show similar values with a mean SSA(532 nm) of $0.90 \pm 0.06$ and a somewhat lower SSA of $0.88 \pm 0.05$ for air masses from polluted source regions. However, SSA values as low as 0.8 have been also found for air masses from IGP (Müller et al., 2003).

SSA values in an altitude range from 1 to $3 \mathrm{~km}$ during INDOEX were found to be $0.85 \pm 0.06$ at $550 \mathrm{~nm}$ for ambient atmospheric conditions (Sheridan et al., 2002), comparable to the present results. The fairly high SD for some of the determined SSA values will lead to an increase in uncertainty of the lidar-derived absorption. The uncertainty of the lidarderived absorption was calculated to be as high as $50 \%$ in some cases (error propagation) and therefore set to $50 \%$.

Since the FT was never influenced by air masses from the Arabian Sea during CARDEX, typical examples for FT air from IGP and southern India are shown in the following in combination with the evaluation of the different methods for deriving profiles of particle absorption coefficients.

\subsubsection{Case study with air masses from the Indo-Gangetic Plain in the free troposphere}

Figure 6 gives an example of vertical profiles of microphysical and optical properties for the end of the campaign (24 March 2012) showing the $\mathrm{PM}_{10}$ particle number concentration for ascending (upleg) and descending (downleg) flights, the relative humidity, the lidar extinction coefficient (with a lidar ratio of $65 \mathrm{sr}$ or AOD constrained), scattering coefficient calculated using Mie theory and absorption coef- 

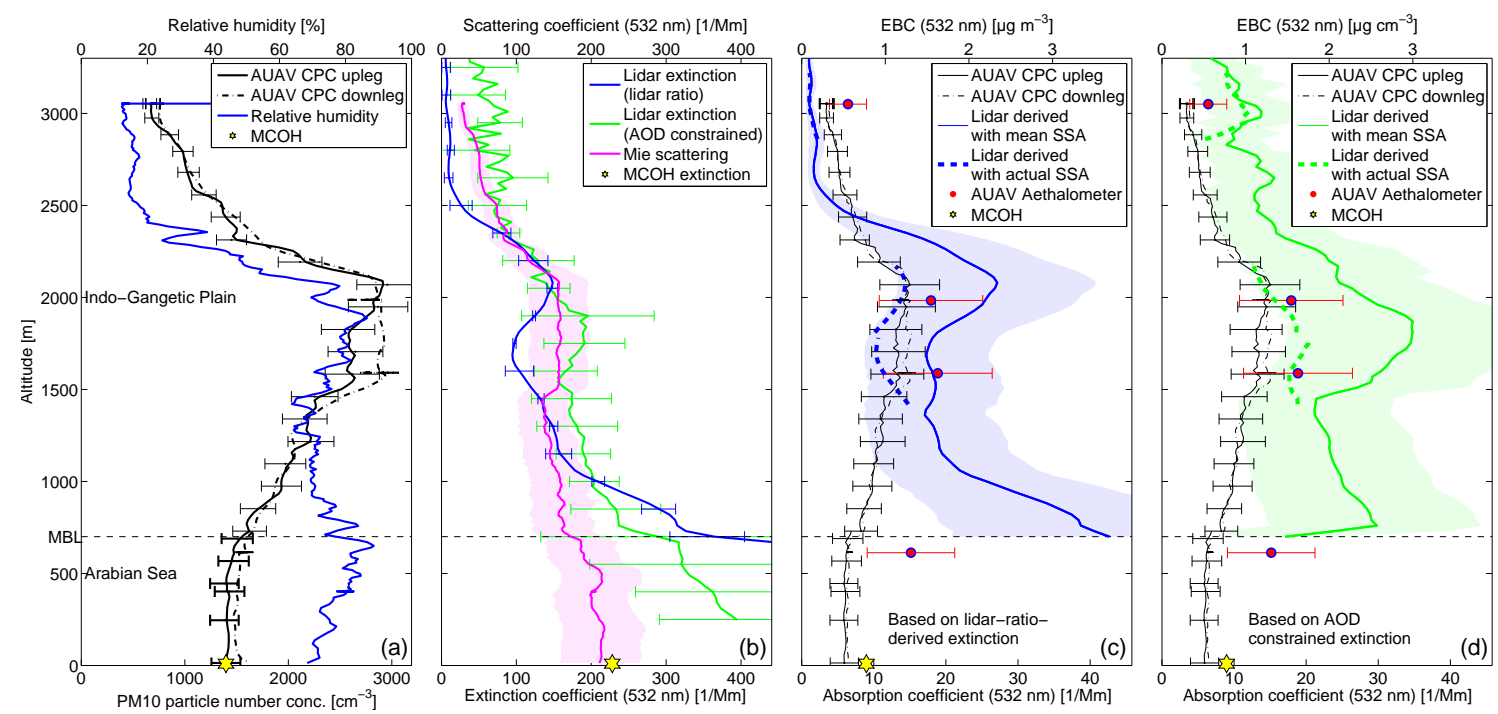

Figure 6. 24 March 2012. (a) Profile of $\mathrm{PM}_{10}$ particle number concentration measured by AUAV CPC for upleg (black solid) and downleg (black dashed) flights and vertical relative humidity profile (blue). (b) Profile of particle extinction coefficient measured with the miniMPL (blue), scattering coefficient calculated with Mie theory (magenta). (c) Profile of particle absorption coefficient and EBC measured by an onboard aethalometer (red dots), estimated from lidar measurements (blue) with mean SSA and 50\% uncertainty (blue shading), estimated from lidar measurements with actual SSA (blue dashed) and AUAV CPC approach (black). (d) Same as (c) but with lidar extinction coefficient constrained by AERONET AOD (green and green dashed).

ficients measured directly onboard the AUAVs and at $\mathrm{MCOH}$ as well as calculated using either the lidar-derived extinction coefficient (and SSA values for different altitude regions) or the measured particle number concentration (and the linear relation presented in Table 3) (see Sect. 2). Figure 6 shows also the EBC profile calculated from the specific MAE for CARDEX (see Sect. 3.3). The optical properties are given for $532 \mathrm{~nm}$.

On 24 March, air masses were coming from AS in the MBL and from IGP in the FT. The FT air mass travelled above the IGP at $3-4.5 \mathrm{~km}$ height above mean sea level for 2 days, followed by a 3-day travel above the Bay of Bengal in $2-3 \mathrm{~km}$. A distinct elevated aerosol layer with high aerosol concentration between 1500 and $2300 \mathrm{~m}$ was detected with the onboard CPC (Fig. 6a). The calculated Mie scattering coefficients less clearly indicate such a peak of particle scattering coefficients in the same region. High Mie scattering coefficients in the MBL with lower particle number concentration are likely a result of scattering from larger particles such as dust or sea salt. This assumption can be supported by the trajectory height information which shows an air mass transport close to the ground prior to arrival.

Large extinction coefficients in the MBL (Fig. 6b) can either be caused by dust or sea salt particles and/or high relative humidity and haze (RH $\approx 90 \%$ in MBL), leading to high backscatter signals or by instrument issues. With the given analytical method for determining absorption coefficients, a humidity-caused signal can not be distinguished from an aerosol signal. The increasing extinction coefficients mea- sured by the lidar below $1000 \mathrm{~m}$ can not be related to aerosols given the nearly constant aerosol number concentration in the MBL. Lidar-derived absorption coefficents are therefore only given for the FT.

The extinction coefficients derived with a given lidar ratio of $65 \mathrm{sr}$ (Fig. 6b, blue line) show an increase at around $2000 \mathrm{~m}$ which indicates that the lidar measurements capture an elevated aerosol layer. However, the aerosol layer seems to be thinner compared to the one seen by in situ measurements but the difference in timing of the measurements must also be considered. The lidar profile shown was measured about $8 \mathrm{~h}$ later than the flight time to avoid clouds and strong background noise from incoming sun light. Closer investigation of the timeseries of the lidar signal indicates that the elevated aerosol, measured by the flights, weakened significantly during the day. The extinction coefficient profile derived with the lidar ratio most likely captured a newly evolved aerosol layer (compare to Fig. S2).

Figure $6 \mathrm{~b}$ also shows the lidar extinction coefficients constrained by co-located AOD measurements (green line). The advantage here is that a lidar profile temporally close to the flight time could be chosen, resulting in a better agreement to the scattering coefficients calculated by Mie theory.

The two right panels of Fig. 6 show the results from the different methods of absorption coefficient profiling and subsequent EBC determination. The lidar-derived absorption coefficient is shown with a $50 \%$ uncertainty range which includes the high uncertainty of the SSA determination. The temporal variance of the extinction coefficient profiles may 

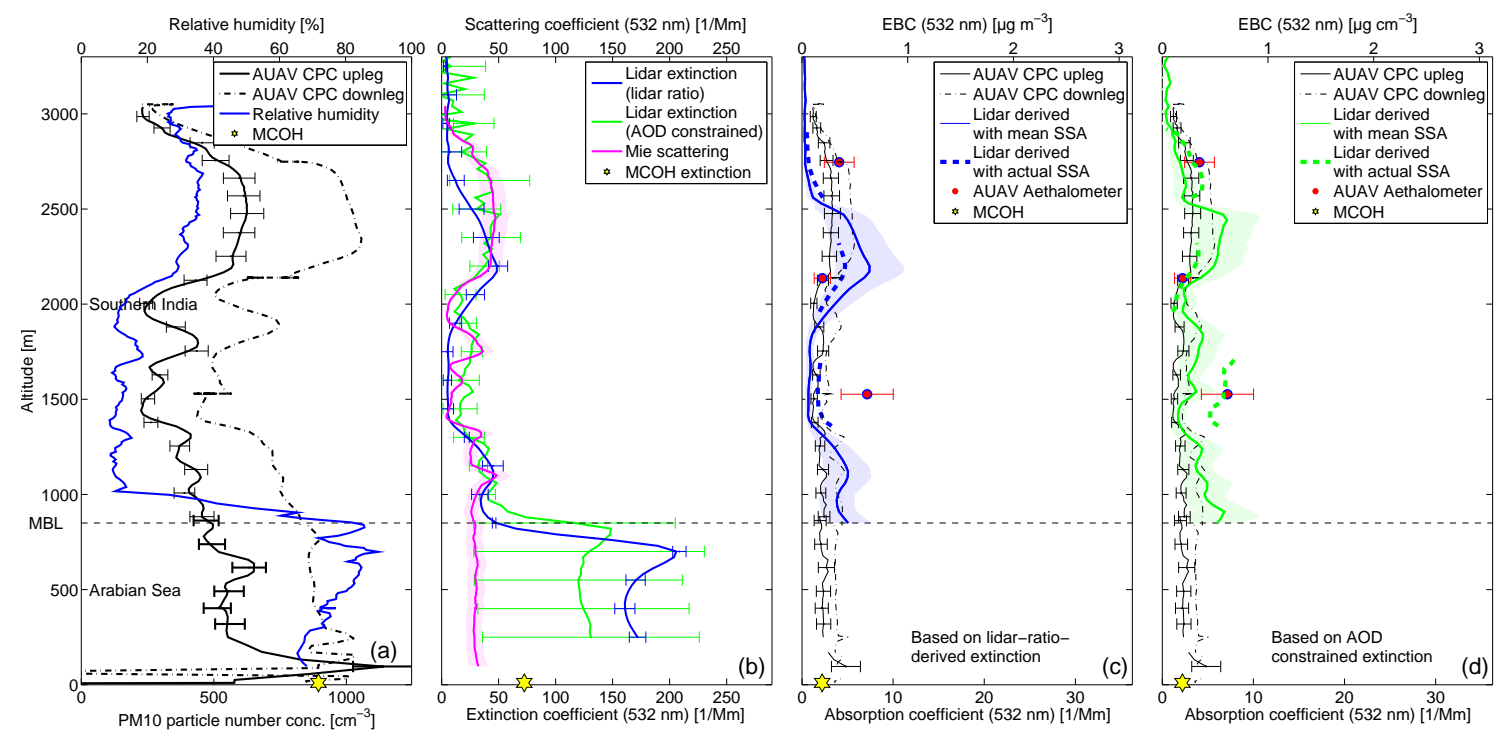

Figure 7. 4 March 2012. (a) Profile of PM $_{10}$ particle number concentration measured by AUAV CPC for upleg (black solid) and downleg (black dashed) flights and relative humidity profile (blue). (b) Profile of particle extinction coefficient measured with the miniMPL (blue), scattering coefficient calculated with Mie theory (magenta). (c) Profile of particle absorption coefficient and EBC measured by an onboard aethalometer (red dots), estimated from lidar measurements (blue) with mean SSA and $50 \%$ uncertainty (blue shading), estimated from lidar measurements with actual SSA (blue dashed) and AUAV CPC approach (black). (d) Same as (c) but with lidar extinction coefficient constrained by AERONET AOD (green and green dashed).

add more uncertainty. The absorption coefficients derived from lidar measurements (with lidar ratio) and mean SSA values seem to capture the actual measured absorption coefficients well (red dots). However, it is not consistent with the profile of the AUAV CPC derived absorption coefficient below $1500 \mathrm{~m}$. High relative humidities towards the top of the MBL may have caused a strong backscattering signal and hence a strong lidar-derived particle absorption coefficient. The lidar-derived absorption coefficients based on extinction coefficients constrained by AERONET AOD and mean SSA overestimate the particle absorption coefficients compared to the in situ measurements (see Fig. 6d). It seems that in general the climatological mean SSA values are too low for this specific day, which might be because of high relative humidities throughout the FT.

A partly plotted particle absorption coefficient profile (blue and green dashed lines) shows the lidar-derived absorption coefficient between 1500 and $2500 \mathrm{~m}$ calculated with the actual SSA, which was determined from the Mie scattering coefficient and the in situ absorption coefficient measurements at the altitudes where SSA values are available. Lower lidar-derived absorption coefficients (with real SSA) indicate that the SSA actually was larger than the mean value for this altitude range on the flight day. Especially the lidarderived absorption coefficient profile with real SSA in Fig. 6d represents the in situ measurements well inside the elevated aerosol layer.

\subsubsection{Case study with air masses from southern India in the free troposphere}

Figure 7 shows the corresponding profiles as in Fig. 6 for a day with air masses from southern India in the FT. Significantly lower particle number concentration, Mie scattering, particle extinction as well as absorption coefficients were detected through the whole column on 4 March compared to 24 March 2012. EBC values are calculated to be below $1 \mu \mathrm{g} \mathrm{m}^{-3}$. However, a weak elevated aerosol layer can be seen between 2000 and $3000 \mathrm{~m}$. Typically, the aerosol number concentration on average decreases constantly with height in air masses from southern India (see Fig. 5) but 4 March shows the highest aerosol number concentration in the free troposphere for this type of air mass (see Fig. 3). The weak elevated aerosol layer can be explained by forest fires in southern India which occurred in the beginning of March, as discussed by Chakrabarty et al. (2014). Altitude resolved trajectories verified that the FT air mass travelled at 3-4 km above mean sea level above the forest fire location 2 days before arriving at $\mathrm{MCOH}$.

The lidar extinction and lidar-derived absorption coefficients also indicate the presence of this aerosol layer. The lidar profile with a given lidar ratio of $50 \mathrm{sr}$ was taken around $6 \mathrm{~h}$ after the flight measurements in this case, which explains the vertical shift of the aerosol layer. A strong increase in lidar extinction coefficients for both methods in the MBL is related to increasing relative humidity towards the MBL. The 

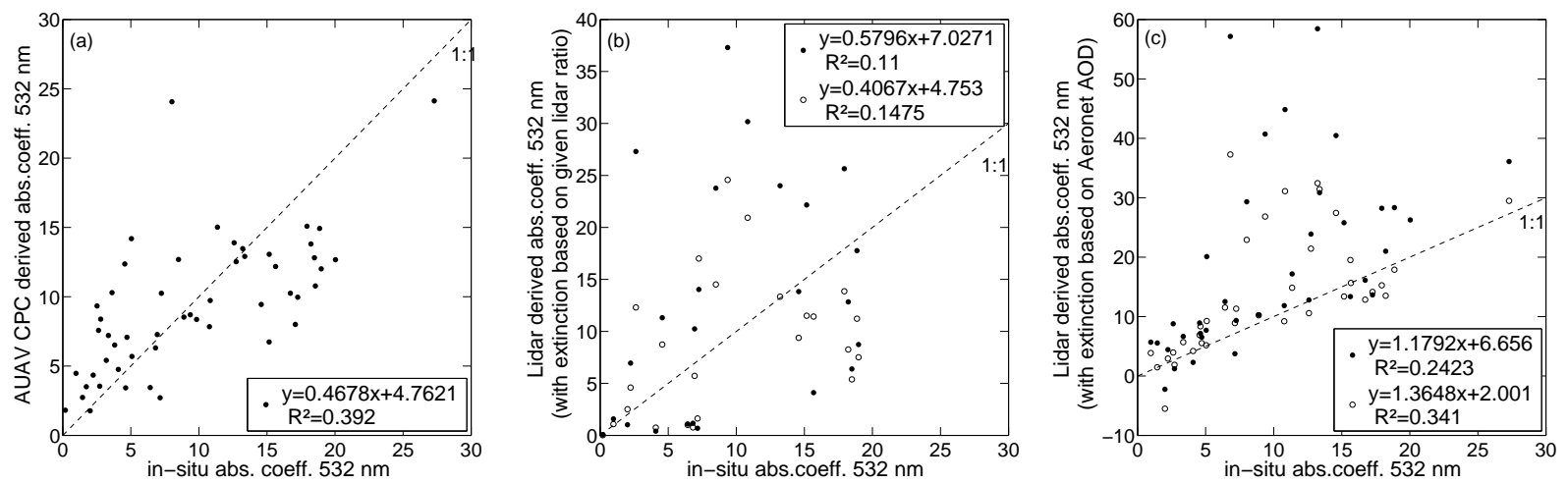

Figure 8. Scatter plot of (a) AUAV CPC derived absorption and in situ absorption coefficients, (b) Lidar-derived absorption coefficients with extinction coefficients based on a given lidar ratio depending on air mass source region and source-specific SSA (closed circles) or actual SSA (open circles) against the in situ absorption coefficients and (c) Lidar-derived absorption coefficients with extinction coefficients constrained by the AERONET AOD and source-specific SSA (closed circles) or actual SSA (open circles) against the in situ absorption coefficients. Particle absorption coefficients are given for $532 \mathrm{~nm}$.

relative humidity is below $40 \%$ in the FT, while it is up to $90 \%$ in the MBL.

The rightmost panel shows the lidar-derived absorption coefficient profile which was calculated from the lidar extinction coefficients constrained by the AERONET AOD instead of using a given lidar ratio. Since this profile is determined at the same time as the flights a better agreement between in situ measured and lidar-derived absorption coefficients is achieved. The relatively high in situ absorption coefficient at around $1500 \mathrm{~m}$ can only be achieved with the lidar-derived absorption coefficients calculated with the actual SSA. This indicates that the determination of the SSA is the critical factor in the absorption coefficient calculation. On the other hand the actual measured absorption coefficient may be biased high since no indication for high particle absorption at that altitude can be seen in the particle number concentration profile.

\subsubsection{Comparison of absorption coefficients derived with different methods}

Figure 8 shows a comparison of the particle absorption coefficients derived from the different methods and the in situ measured absorption coefficients at $532 \mathrm{~nm}$ (see Sect. 2.7). The correlation between the calculated and the in situ measured absorption coefficients is relatively weak in all cases $\left(R^{2} \leq 0.39\right)$.

The particle absorption coefficients calculated from the relation with the particle number concentration (see Table 3) shows fairly good agreement with the $1: 1$ line in Fig. 8a. The linear regression is statistically significant at the $95 \%$ significance level. The absorption coefficient was calculated for different source regions based on surface measurements. However, air masses from a certain source region might not have the same optical properties in the FT as in the MBL (Corrigan et al., 2008). Further, the correlation shown in Ta-

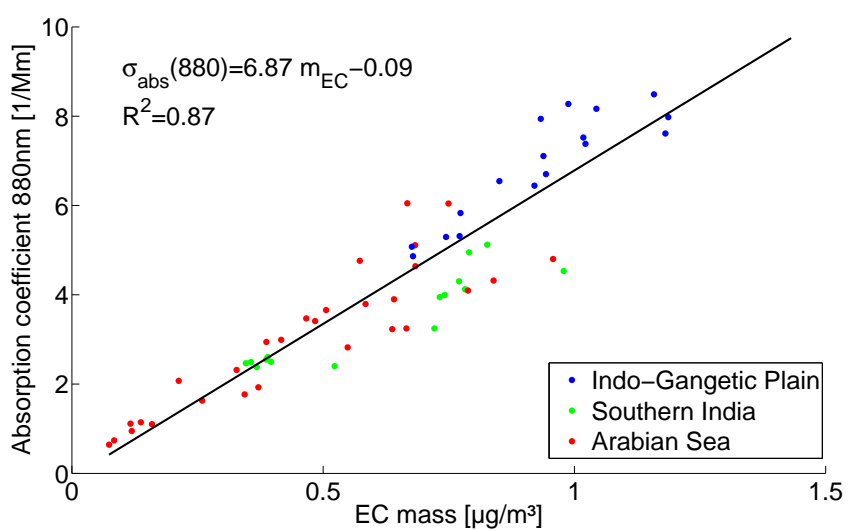

Figure 9. Particle absorption coefficient for $880 \mathrm{~nm}$ against $\mathrm{PM}_{2.5}$ EC mass concentration, grouped by source regions according to Fig. 2.

ble 3 might be better if several years of observations could have been considered.

Except for some outliers, the absorption coefficients calculated with the AOD constrained particle extinction coefficients follow the $1: 1$ line fairly well (Fig. 8c). The correlation coefficient is here the best for the particle absorption coefficients calculated with the actual SSA (open circles). The regression analysis is statistically significant for the slope coefficient for both calculation alternatives.

The rather high lidar-derived absorption coefficients above $50 \mathrm{M} \mathrm{m}^{-1}$ were found to be from 23 March 2012. This AUAV flight day was classified as a day with air masses from the IGP. Compared to other IGP influenced days, the air mass was transported rather over central India and the western IGP but was not affected by the highly polluted eastern outflow of the IGP. A dust influence can also not be excluded. Thus, the utilized mean SSA are likely to be underestimating the real 
Table 4. Relation between the particle absorption coefficient at $880 \mathrm{~nm}$ and the $\mathrm{PM}_{2.5}$ EC mass concentration for different source regions.

\begin{tabular}{lll}
\hline Source region & $\sigma_{\mathrm{abs}}(880 \mathrm{~nm})=a m_{\mathrm{EC}}+b\left[\mathrm{Mm}^{-1}\right]$ & $R^{2}$ \\
\hline All together & $\sigma_{\mathrm{abs}}=6.9 m_{\mathrm{EC}}-0.09$ & 0.81 \\
Indo-Gangetic Plain & $\sigma_{\mathrm{abs}}=6.6 m_{\mathrm{EC}}+0.67$ & 0.81 \\
Southern India & $\sigma_{\mathrm{abs}}=4.3 m_{\mathrm{EC}}+0.8$ & 0.83 \\
Arabian Sea & $\sigma_{\mathrm{abs}}=5.6 m_{\mathrm{EC}}+0.4$ & 0.79 \\
\hline
\end{tabular}

SSA during this day, hence producing high particle absorption.

The absorption coefficients calculated using a given lidar ratio show the poorest correlation with the in situ observations and the regression is not statistically significant at the $95 \%$ significance level (see Fig. 8b). One main issue may be the time difference between the flight observations and the lidar profiling. However, the lidar-derived absorption coefficient profiles follow the general structure of the in situ measured aerosol profiles in the free troposphere (see Figs. 6 and 7).

A somewhat better agreement was achieved with the use of the actual SSA (see Fig. 8b, open circles). It seems that the correct determination of the SSA is a crucial point in deriving the absorption coefficients from lidar measurements. A longer time series of vertical in situ measurements could help to obtain a better source-dependent SSA profile. Direct measurements of vertical scattering coefficient profiles as already performed for other aircraft campaigns (e.g. Sheridan et al., 2012; Johnson et al., 2008) would reduce the uncertainty in absorption coefficient calculations.

The rather poor correlation between the in situ measurements and the other methods for determining the absorption coefficient does not imply that the methods are unusable. Even the onboard in situ measurements, which were used as reference, can have uncertainties of up to $40 \%$ and offer a poor constraint on the lidar derived absorption coefficient profiles. The comparison however indicates that the general vertical structure was captured.

\subsection{CARDEX MAE}

Figure 9 shows the comparison between measured EC mass $\left(\mathrm{PM}_{2.5}\right)$ and particle absorption coefficients at $880 \mathrm{~nm}$. There is a clear linear relation between the particle absorption coefficient at $880 \mathrm{~nm}$ and the EC mass (see Sect. 2.8). The highest particle absorption coefficients and EC mass was measured during periods with air masses from IGP in the MBL, while the lowest values for both particle properties were detected with AS air mass influences, as discussed in Sect. 3.1.

A specific MAE value for $\mathrm{MCOH}$ during the dry monsoon season can be calculated with the method described in Sect. 2.8 (similar to Corrigan et al., 2006). Without any distinction between different source regions, a MAE for EBC at
$880 \mathrm{~nm}$ is calculated to be $6.9 \mathrm{~m}^{2} \mathrm{~g}^{-1}$. Adjusted to $520 \mathrm{~nm}$ the EBC MAE would be $11.6 \mathrm{~m}^{2} \mathrm{~g}^{-1}$. The adjustment was performed according to Yang et al. (2009) with the assumption that the absorption Ångström exponent is 1 for BC particles.

Bond and Bergstrom (2006) gave an MAE estimate for freshly emitted carbonaceous particles of $7.5 \pm 1.2 \mathrm{~m}^{2} \mathrm{~g}^{-1}$ for $550 \mathrm{~nm}$. MAE values for internally mixed carbonaceous aerosol is estimated to be around $12.5 \mathrm{~m}^{2} \mathrm{~g}^{-1}$ (Bond et al., 2013). The overall EBC MAE for CARDEX of $11.6 \mathrm{~m}^{2} \mathrm{~g}^{-1}$ represents processed carbonaceous aerosol particles and is also close to the general estimate by Bond et al. (2013).

Furthermore, specific MAE values for each air mass can be determined using the relation between the $\sigma_{\text {abs }}(880 \mathrm{~nm})$ and EC mass (see Table 4). Assuming that the slope of the linear relation determines the MAE, air masses from IGP have an $\operatorname{MAE}(880 \mathrm{~nm})$ of $6.6 \mathrm{~m}^{2} \mathrm{~g}^{-1}\left(\operatorname{MAE}(520 \mathrm{~nm})=11.2 \mathrm{~m}^{2} \mathrm{~g}^{-1}\right)$, which is also similar to the overall MAE of $6.9 \mathrm{~m}^{2} \mathrm{~g}^{-1}$. Air masses from SI and AS have a significantly lower MAE for $880 \mathrm{~nm}$ with 4.3 and $5.6 \mathrm{~m}^{2} \mathrm{~g}^{-1}(\operatorname{MAE}(520 \mathrm{~nm})=$ $\left.7.3 \mathrm{~m}^{2} \mathrm{~g}^{-1}, \operatorname{MAE}(520 \mathrm{~nm})=9.5 \mathrm{~m}^{2} \mathrm{~g}^{-1}\right)$, respectively. For the Arabian Sea, the lower MAE could be explained by a larger contribution from bigger particles, such as dust, since the MAE decreases with increasing particle size for $\mathrm{D}_{p} \geq 300 \mathrm{~nm}$ (Bond and Bergstrom, 2006). MAE of dust is in general smaller compared to BC-containing particles as well. Air masses passing over southern India may contain relatively freshly emitted $\mathrm{BC}$ particles and these have in general a lower MAE than particles with a longer transport time (Bond et al., 2013). According to Arnott et al. (2005), various multiple scattering correction factors should be used for different internally mixed aerosols. This attempt might additionally change the determination of MAE additionally.

On the other hand, fairly high intercept values for all three source-specific relations indicate that it is not only the slope that determines the MAE. With a larger data set a more accurate relation could likely be achieved and this will be investigated in future studies. The MAE is used to estimate EBC profiles from the absorption coefficient profiles as described in Sect. 2 and shown in Sect. 3.2.

\section{Summary and conclusion}

This study presented aerosol in situ and lidar-derived measurements, with a focus on aerosol optical properties, from the field campaign CARDEX that took place during the dry monsoon season, February and March 2012, close to the permanent station $\mathrm{MCOH}$ on the northern Maldives island Hanimaadhoo.

Air mass cluster analysis confirmed that elevated aerosol layers occur mainly during air mass influence from the Indian subcontinent. The highest aerosol particle number concentrations through the whole column were found for air masses which passed over the highly polluted Indo-Gangetic Plain 
and which were then transported over the Bay of Bengal to the northern Indian Ocean.

Comparison with previous field campaigns over the same region (INDOEX in 1999 and MAC in 2006) were presented. Elevated aerosol layers were consistently found in in situ particle number concentration measurements both during MAC and CARDEX, but not during INDOEX. Particle absorption coefficients were lower in CARDEX compared to INDOEX and MAC while the scattering coefficients were higher, i.e., the SSA was higher during CARDEX.

A main aim of the study was to investigate the possibility of using ground-based lidar measurements to determine the vertical distribution of absorbing aerosols. In situ AUAV-based measurements of absorption coefficient profiles were thus compared with lidar-derived absorption coefficient profiles, where the latter require input of vertically resolved SSA values. SSA values for different altitude intervals and different air masses were estimated using in situ observations of particle absorption coefficients and scattering coefficients calculated using Mie theory. The evaluation of the lidar-derived absorption coefficient profiles showed a large sensitivity to the given SSA values. Using campaignaveraged, source-specific, SSA values, the overall shape of the lidar-derived absorption coefficient profile appeared reasonable, but the correlation with the in situ measured absorption coefficients was rather poor $\left(R^{2}=0.15\right)$. Constraining the lidar-derived extinction coefficients to AERONET observed AOD improved the correlation with observations $\left(R^{2}=0.34\right)$ which is likely due to closer agreement in time with the measurement flights. Results with better statistical significance were found if the absorption coefficient profile is determined from simple linear regression with the total particle number. However, the surface-based regression may not be valid for the free troposphere.

Determination of vertical profiles of absorption coefficients remains difficult and involves high uncertainties in general. Longer time series of vertically resolved SSA values may help improve the lidar-derived absorption coefficient profiles.

Surface measurements of the particle absorption coefficient and elemental carbon mass concentration were used to determine a specific mass absorption efficiency (MAE) for the northern Indian Ocean during the dry monsoon season. A mean MAE of $11.6 \mathrm{~m}^{2} \mathrm{~g}^{-1}$ for $520 \mathrm{~nm}$ was found. This result represents approximately internally mixed BC containing particles according to Bond et al. (2013) who gave an estimate of $12.5 \mathrm{~m}^{2} \mathrm{~g}^{-1}$ for processed carbonaceous aerosol. Lower MAE values were found for air masses originating from southern India and the Arabian Sea. MAE is necessary for calculating equivalent black carbon concentrations from absorption coefficient measurements.

The Supplement related to this article is available online at doi:10.5194/acp-16-1045-2016-supplement.
Acknowledgements. The CARDEX field campaign was sponsored and funded by the National Science foundation and conducted by the Scripps Institution of Oceanography at the University of California at San Diego in collaboration with the Desert Research Institute, Stockholm University, Argonne National Laboratory and the Max Planck Institute at Hamburg. V. Ramanathan is the principal investigator of CARDEX, E. Wilcox is the Co-PI and H. Nguyen was the field director who conducted the campaign with full support by the government of Maldives. We thank the AERONET PI Brent Holben for his effort in establishing and maintaining the MCOHanimaadhoo site.

C. Bosch, A. Andersson and Ö. Gustafsson also acknowledge financial support from the Swedish funding agencies FORMAS (2142009-970), STEM (35450-2), and Sida (AKT-2010-038). C. Bosch acknowledges additional financial support from EU Marie Curie Programme (PIEF-GA-2011-198507).

Full details of the CARDEX campaign can be found in: http: //www-ramanathan.ucsd.edu/files/CARDEX_prop_Jun_20.pdf. This study is Paper\#2 from the CARDEX campaign.

Edited by: M. Tesche

\section{References}

Anderson, T. L. and Ogren, J. A.: Determining aerosol radiative properties using the TSI 3568 Integrating Nephelometer, Aerosol Sci. Tech., 29, 57-69, 1998.

Andreae, M. O. and Ramanathan, V.: Climates dark forcings, Science, 340, 280-281, 2013.

Arnott, W. P., Hamasha, K., Moosmüller, H., Sheridan, P. J., and Ogren, J. A.: Towards aerosol light-absorption measurements with 7-wavelength Aethalometer: evaluation with a photoacoustic instrument and 3-wavelength Nephelometer, Aerosol Sci. Tech., 39, 17-29, 2005.

Babu, S., Satheesh, S., Moorthy, K., Dutt, C., Nair, V. S., Alappattu, D. P., and Kunhikrishnan, P.: Aircraft measurements of aerosol black carbon from a coastal location in the north-east part of peninsular India during ICARB, J. Earth Syst. Sci., 117, 263271, 2008.

Babu, S. S., Sreekanth, V., Moorthy, K. K., Mohan, M., Kirankumar, N., Subrahamanyam, D. B., Gogoi, M. M., Kompalli, S. K., Beegum, N., Chaubey, J. P., Kumar, V. A., and Manchanda, R. K.: Vertical profiles of aerosol black carbon in the atmospheric boundary layer over a tropical coastal station: perturbations during an annular solar eclipse, Atmos. Res., 99, 471-478, 2011.

Bond, T. C. and Bergstrom, R. W.: Light absorption by carbon particle: an investigative review, Aerosol Sci. Tech., 40, 27-67, 2006.

Bond, T. C., Covert, D. S., and Müller, T.: Truncation and AngularScattering Corrections for Absorbing Aerosol in the TSI 3563 Nephelometer, Aerosol Sci. Tech., 43, 866-871, 2009.

Bond, T. C., Doherty, S. J., Fahey, D. W., Forster, P. M., Berntsen, T., DeAngelo, B. J., Flanner, M. G., Ghan, S., Kärcher, B., Koch, D., Kinne, S., Kondo, Y., Quinn, P. K., Sarofim, M. C., Schultz, M. G., Schulz, M., Venkataraman, C., Zhang, H., Zhang, S., Bellouin, N., Guttikunda, S. K., Hopke, P. K., Jacobson, M. Z., Kaiser, J. W., Klimont, Z., Lohmann, U., Schwarz, J. P., Shindell, D., Storelvmo, T., Warren, S. G., and Zender, C. S.: Bounding the role of black carbon 
in the climate system: a scientific assessment, J. Geophys. Res.Atmos., 118, 5380-5552, 2013.

Bosch, C., Andersson, A., Kirillova, E., Budhavant, K., Tiwari, S., Praveen, P. S., Russel, L. M., Beres, N. D., Ramanathan, V., and Gustafsson, Ö.: Source-diagnostic dual-isotope composition and optical properties water-soluble organic carbon and elemental carbon in South Asian outflow intercepted over the Indian Ocean, J. Geophys. Res., 119, 11743-11759, 2014.

Boucher, O., Randall, D., Artaxo, P., Bretherton, C., Feingold, G., Forster, P., Kerminen, V.-M., Kondo, Y., Liao, H., Lohmann, U., Rasch, P., Satheesh, S. K., Sherwood, S., Stevens, B., and Zhang, X. Y.: Clouds and aerosols, in: Climate Change 2013: The Physical Science Basis. Contribution of Working Group I to the Fifth Assessment Report of the Intergovernmental Panel on Climate Change, Cambridge University Press, Cambridge, UK and New York, NY, USA, 614-623, 2013.

Chakrabarty, R. K., Nicholas, D. B., Moosmüller, H., China, S., Mazzoleni, C., Dubey, M. K., Liu, L., and Mishchenko, I.: Soot superaggregates from flaming wildfires and their direct radiative forcing, Nature, scientific report, 4, 5508, doi:10.1038/srep05508, 2014.

Clarke, A. D., Howell, S. G., Quinn, P. K., Bates, T. S., Ogren, J., Andrews, E. A. J., Massling, A., Mayol-Bracero, O., Maring, H., Savoie, D., and Cass, G. R.: INDOEX aerosl: a comparison and summary of chemical, microphysical, and optical properties observed from land, ship, and aircraft, J. Geophys. Res., 107, D198033, doi:10.1029/2001JD000572, 2002.

Collins, D. R., Johnsson, H. H., Seinfeld, J. H., Flagan, R. C., Gasso, S., Hegg, D. A., Russell, P. B., Schmid, B., Livingston, J. M., Öström, E., Noone, K. J., Russel, L. M., and Putaud, J. P.: In situ aerosol-size distributions and clear-column radiative closure during ACE-2, Tellus B, 52, 498-525, 2000.

Corrigan, C. E., Ramanathan, V., and Schauer, J. J.: Impact of monsoon transitions on the physical and optical properties of aerosols, J. Geophys. Res., 111, D18208, doi:10.1029/2005JD006370, 2006.

Corrigan, C. E., Roberts, G. C., Ramana, M. V., Kim, D., and Ramanathan, V.: Capturing vertical profiles of aerosols and black carbon over the Indian Ocean using autonomous unmanned aerial vehicles, Atmos. Chem. Phys., 8, 737-747, doi:10.5194/acp-8-737-2008, 2008.

de Reus, M., Krejci, R., Williams, J., Fischer, H., Scheele, R., and Ström, J.: Vertical and horizontal distributions of the aerosol number concentration and size distribution over the northern Indian Ocean, J. Geophys. Res., 106, 28629-28641, 2001.

Dey, S. and Di Girolamo, L.: A climatology of aerosol optical and microphysical properties over the Indian subcontinent from 9 years (2000-2008) of Multiangle Imaging Spectroradiometer (MISR) data, J. Geophys. Res., 115, D15204, doi:10.1029/2009JD013395, 2010.

Draxler, R. R.: HYSPLIT4 User's Guide, Tech. Rep., NOAA Air Resources Laboratory, Silver Spring, MD, 1999.

Eldering, A., Ogren, J. A., Chowdhury, Z., Hughes, L. S., and Cass, G. R.: Aerosol optical properties during INDOEX based on measured aerosol particle size and composition, J. Geophys. Res., 107, D22,8001, doi:10.1029/2001JD001672, 2002.

Engström, J. E. and Leck, C.: Reducing uncertainties associated with filter-based optical measurements of light absorbing car- bon particles with chemical information, Atmos. Meas. Tech., 4, 1553-1566, doi:10.5194/amt-4-1553-2011, 2011.

Fernald, F. G.: Analysis of atmospheric lidar observations: Some comments, Appl. Opt., 23, 652-653, 1984.

Fitzgerald, J., Hoppel, W., and Vietti, M.: The size and scattering coefficient of urban aerosol particle at Washington, DC as a function of relative humidty, J. Atmos. Sci., 39, 1838-1852, 1982.

Franke, K., Ansmann, A., Müller, D., Althausen, D., Venkataraman, C., Reddy, M. S., Wagner, F., and Scheele, R.: Optical properties of the Indo-Asian haze layer over the tropical Indian Ocean, J. Geophys. Res., 108, D24059, doi:10.1029/2002JD002473, 2003.

Granier, C., Bessagnet, B., Bond, T., D’Angiola, A., Denier van der Gon, H., Frost, G. J., Heil, A., Kaiser, J. W., Kinne, S., Klimont, Z., Kloster, S., Lamarque, J.-F., Liousse, C., Masui, T., Meleux, F., Mieville, A., Ohara, T., Raut, J.-C., Riahi, K., Schultz, M. G., Smith, S. J., Thompson, A., van Aardenne, J., van der Werf, G. R., and van Vuuren, D. P.: Evolution of anthropogenic and biomass burning emissions of air pollutants at global and regional scales during the 1980-2010 period, Climatic Change, 109, 163-190, 2011.

Gustafsson, Ö., Kruså, M., Zencak, Z., Sheesley, R. J., Granat, L., Engström, E., Praveen, P. S., Rao, P. S. P., Leck, C., and Rodhe, H.: Brown cloud over south Asia: biomass or fossil fuel combustion, Science, 323, 495-498, 2009.

Heintzenberg, J., Covert, D. C., and Van Dingenen, R.: Size distribution and chemical composition of marine aerosols: a compilation and review, Tellus B, 52, 1104-1122, 2000.

Holben, B. N., Eck, T. F., Slutsker, I., Tanre, D., P., B. J., Setzer, A., Vermote, E., Reagan, J. A., Kaufman, Y. J., Nakajima, T., Lavenu, F., Jankowiak, I., and Smirnov, A.: Aeronet - a federated instrument network and data archive for aerosol characterization, Remote Sens. Environ., 66, 1-16, 1998.

Holland, G. H., Webster, P. J., Curry, J. A., Tyrell, G., Gauntlett, D., Brett, G., Becker, J., Hoag, R., and Vaglienti, W.: The aerosonde robotic aircrafts: a new paradigm for environmental observations, B. Am. Meteorol. Soc., 82, 889-901, 2001.

Johnson, B. T., Osborne, S. R., Haywood, J. M., and Harrison, M. A. J.: Aircraft measurements of biomass burning aerosol over West Africa during DABEX, J. Geophys. Res., 113, D00C06, doi:10.1029/2007JD009451, 2008.

King, M. D., Menzel, W. P., Kaufman, Y. J., Tanre, D., Gao, B.C., Platnick, S., Ackerman, S. A., Remer, L. A., Pincus, R., and Hubanks, P. A.: Cloud and aerosol properties, precipitable water, and profiles of temperature and water vapor from MODIS, IEEE T. Geosci. Remote, 41, 442-458, 2003.

Klett, J. D.: Stable analytical inversion solution for processing lidar returns, Appl. Opt., 20, 211-220, 1981

Lawrence, M. G. and Lelieveld, J.: Atmospheric pollutant outflow from southern Asia: a review, Atmos. Chem. Phys., 10, 1101711096, doi:10.5194/acp-10-11017-2010, 2010.

Lelieveld, J., Crutzen, P. J., Ramanathan, V., Andreae, M. O., Brenninkmeijer, C. A. M., Campos, T., Cass, G. R., Dickerson, R., Fischer, H., de Gouw, J. A., Hansel, A., Jefferson, M. G., Kley, D., de Laat, A. T. J., Lal, S., Lawrence, M. G., Lobert, J. M., mayol Bracero, O. L., Mitra, A. P., Novakov, T., Oltmans, S. J., Prather, K. A., Reiner, T., Rodhe, H., Scheeren, H. A., Sikka, D., and Williams, J.: The Indian Ocean Experiment: widespread air 
pollution from south and southeast Asia, Science, 291, 10311036, 2001.

Maßling, A., Wiedensohler, A., Busch, B., Neusüß, C., Quinn, P., Bates, T., and Covert, D.: Hygroscopic properties of different aerosol types over the Atlantic and Indian Oceans, Atmos. Chem. Phys., 3, 1377-1397, doi:10.5194/acp-3-1377-2003, 2003.

Moorthy, K. K., Sunilkumar, S. V., Pillai, P. S., Parameswaran, K., Nair, P. R., Ahmed, Y. N., Ramgopal, K., Narasimhulu, K., Reddy, R. R., Vinoj, V., Satheesh, S. K., Niranjan, K., Rao, B. M., Brahmanandam, P. S., Saha, A., Badarinath, K. V. S., Kiranchand, T. R., and Latha, K. M.: Wintertime spatial characteristics of boundary layer aerosols over peninsular India, J. Geophys. Res.-Atmos., 110, D08207, doi:10.1029/2004JD005520, 2005.

Moorthy, K. K., Satheesh, S. K., Babu, S. S., and Dutt, C. B. S.: Integrated Campaign for Aerosols, Gases and Radiation Budget (ICARB): an overview, J. Earth Syst. Sci., 117, 243-262, 2008.

Moorthy, K. K., Babu, S. S., Manoj, M. R., and Satheesh, S. K.: Buildup of aerosols over the Indian region, Geophys. Res. Lett., 40, 1011-1014, 2013.

Müller, D., Franke, K., Ansmann, A., and Althausen, D.: Indo-Asian pollution during INDOEX: Microphysical particle properties and single-scattering albedo inferred from multiwavelength lidar observations, J. Geophys. Res., 108, 4600, doi:10.1029/2003JD003538, 2003.

Müller, D., Ansmann, A., Mattis, I., Tesche, M., Wandinger, U., Althausen, D., and Pisani, G.: Aerosol-type-dependent lidar ratios observed with Raman lidar, J. Geophys. Res. Atmos., 112, D16202, doi:10.1029/2006JD00829, 2007.

Liu, Y. and Daum, P. H.: The effect of refractive index on size distributions and light scattering coefficients derived from optical particle counters, J. Aerosol. Sci., 31, 945-957, 2000.

Oshima, N., Kondo, Y., Moteki, N., Takegawa, N., Koike, M., Kita, K., Matsui, H., Kajino, M., Nakamura, H., Jung, J. S., and Kim, Y. J.: Wet removal of black carbon in Asian outflow: Aerosol Radiative Forcing in East Asia (A-FORCE) aircraft campaign, J. Geophys. Res.-Atmos., 117, D03204, doi:10.1029/2011JD016552, 2012.

Petzold, A., Ogren, J. A., Fiebig, M., Laj, P., Li, S.-M., Baltensperger, U., Holzer-Popp, T., Kinne, S., Pappalardo, G., Sugimoto, N., Wehrli, C., Wiedensohler, A., and Zhang, X.-Y.: Recommendations for reporting "black carbon" measurements, Atmos. Chem. Phys., 13, 8365-8379, doi:10.5194/acp-13-83652013, 2013.

Pistone, K., Praveen, P. S., Thomas, R. M., Ramanathan, V., Wilcox, E., and Bender, F. A.-M.: Observed correlations between aerosol and cloud properties in an Indian Ocean trade cumulus regime, Atmos. Chem. Phys. Discuss., 15, 29347-29402, doi:10.5194/acpd-15-29347-2015, 2015.

Ramana, M. V. and Ramanathan, V.: Abrupt transition from natural to anthropogenic aerosol radiative forcing: observations at the ABC-Maldives Climate Observatory, J. Geophys. Res., 111, D20207, doi:10.1029/2006JD007063, 2006.

Ramanathan, V., Crutzen, P. J., Lelieveld, J., Mitra, A. P., Althausen, D., Anderson, J., Andreae, M. O., Cantrell, W., Cass, G. R., Chung, C. E., Clarke, A. D., Coakley, J. A., Collins, W. D., Conant, W. C., Dulac, F., Heintzenberg, J., Heymsfield, A. J., Holben, B. N., Howell, S. G., Hudson, J., Jayaraman, A., Kiehl, J. T., Krishnamurti, T. N., Lubin, D., McFarquhar, G., Novakov, T., Ogren, J. A., Podgorny, I. A.,
Prather, K. A., Priestley, K., Prospero, J. M., Quinn, P. K., Rajeev, K., Rasch, P., Rupert, S., Sadourny, R., Satheesh, S. K., Shaw, G. E., Sheridan, P., and Valero, F. P. J.: Indian Ocean Experiment: an integrated analysis of the climate forcing and effects of the great Indo-Asian haze, J. Geophys. Res., 106, 2837128398, 2001.

Ramanathan, V., Li, M. V., Ramana, M. V., Praveen, P. S., Kim, D., Corrigan, C. E., and Nguyen, H.: Atmospheric Brown Clouds: Hemispherical and regional variations in long range transport, absorption, and radiative forcing, J. Geophys. Res., 112, D22S21, doi:10.1029/2006JD008124, 2007.

Ramanathan, V., Ramana, M. V., Roberts, G. C., Kim, D., Corrigan, C. E., Chung, C. E., and Winker, D.: Warming trends in Asia amplified by brown cloud solar absorption, Nature, 448, 575-578, 2007.

Ramanathan, V., Thomas, R. M., Praveen, P. S., Nguyen, H. V., Wilcox, E., Bender, F. A.-M., Pistone, K.: Cloud Aerosol Radiative Forcing Dynamics EXperiment (CARDEX), available at: http://www-ramanathan.ucsd.edu/files/CARDEX_prop_Jun_ 20.pdf (last access: 16 December 2015), 2011.

Roberts, G. C., Ramana, M. V., Corrigan, C., Kim, D., and Ramanathan, V.: Simultaneous observations of aerosol-cloudalbedo interactions with three stacked unmanned aerial vehicles, Proc. Natl. Acad. Sci. USA, 105, 7370-7375, 2008.

Samset, B. H., Myhre, G., Herber, A., Kondo, Y., Li, S.-M., Moteki, N., Koike, M., Oshima, N., Schwarz, J. P., Balkanski, Y., Bauer, S. E., Bellouin, N., Berntsen, T. K., Bian, H., Chin, M., Diehl, T., Easter, R. C., Ghan, S. J., Iversen, T., Kirkevåg, A., Lamarque, J.-F., Lin, G., Liu, X., Penner, J. E., Schulz, M., Seland, Ø., Skeie, R. B., Stier, P., Takemura, T., Tsigaridis, K., and Zhang, $\mathrm{K}$.: Modelled black carbon radiative forcing and atmospheric lifetime in AeroCom Phase II constrained by aircraft observations, Atmos. Chem. Phys., 14, 12465-12477, doi:10.5194/acp14-12465-2014, 2014.

Satheesh, S. K., Moorthy, K. K., Babu, S. S., Vinoj, V., and Dutt, C. B. S.: Climate implications of large warming by elevated aerosol over India, Geophys. Res. Lett., 35, L19809, doi:10.1029/2008GL034944, 2008.

Sheridan, P. J., Jefferson, A., and Ogren, J. A.: Spatial variability of submicrometer aerosol radiative properties over the Indian Ocean during INDOEX, J. Geophys. Res., 107, INX2 10-1-INX2 1017, doi:10.1029/2000JD000166, 2002.

Sheridan, P. J., Andrews, E., Ogren, J. A., Tackett, J. L., and Winker, D. M.: Vertical profiles of aerosol optical properties over central Illinois and comparison with surface and satellite measurements, Atmos. Chem. Phys., 12, 11695-11721, doi:10.5194/acp12-11695-2012, 2012.

Spinhirne, J. D.: Micro pulse lidar, IEEE T. Geosci. Remote, 31, 48-55, 1993.

Spinhirne, J. D., Rall, J., and Scott, V. S.: Compact eye-safe lidar systems, The Review of Laser Engineering, 23, 26-32, 1995.

Thomas, R. M., Lehmann, K., Nguyen, H., Jackson, D. L., Wolfe, D., and Ramanathan, V.: Measurement of turbulent water vapor fluxes using a lightweight unmanned aerial vehicle system, Atmos. Meas. Tech., 5, 243-257, doi:10.5194/amt-5-243-2012, 2012.

Titos, G., Jefferson, A., Sheridan, P. J., Andrews, E., Lyamani, H., Alados-Arboledas, L., and Ogren, J. A.: Aerosol light-scattering enhancement due to water uptake during the TCAP campaign, 
Atmos. Chem. Phys., 14, 7031-7043, doi:10.5194/acp-14-70312014, 2014.

Verver, G. H. L., Sikka, D., Lobert, J. M., Stossmeister, G., and Zachariasse, M.: Overview of the meteorological conditions and atmospheric transport processes during INDOEX 1999, J. Geophys. Res., 106, 28399-28413, 2001.

Welton, E. J., Voss, K. J., Gordon, H. R., Maring, H., Smirnov, A., Holben, B., Schmid, B., and Livingston, J. M., Russell, P. B., Durkee, P. A., Formenti, P., and Andreae, M. O.: Ground-based lidar measurements of aerosols during ACE-2: instrument description, results, and comparisons with other ground-based and airborne measurements, Tellus B, 52, 636-651, 2000.

Welton, E. J., Voss, K. J., Quinn, P. K., Flatau, P. J., Markowicz, K., Campbell, J. R., Spinhirne, J. D., Gordon, H. R., and Johnson, J. E.: Measurements of aerosol vertical profiles and optical properties during INDOEX 1999 using micropulse lidars, J. Geophys. Res.-Atmos., 107, INX2-1-INX220, doi:10.1029/2000JD000038, 2002.
Wofsy, S.: HIAPER Pole-to-Pole Observations (HIPPO): finegrained, global-scale measurements of climatically important atmospheric gases and aerosols, Philos. T. R. Soc. A, 369, 20732086, 2011.

Yang, M., Howell, S. G., Zhuang, J., and Huebert, B. J.: Attribution of aerosol light absorption to black carbon, brown carbon, and dust in China - interpretations of atmospheric measurements during EAST-AIRE, Atmos. Chem. Phys., 9, 2035-2050, doi:10.5194/acp-9-2035-2009, 2009.

Zieger, P., Fierz-Schmidhauser, R., Weingartner, E., and Baltensperger, U.: Effects of relative humidity on aerosol light scattering: results from different European sites, Atmos. Chem. Phys., 13, 10609-10631, doi:10.5194/acp-13-10609-2013, 2013. 